\title{
EFFECTIVE RESISTANCE AND INDUCTANCE OF IRON AND BIMETALLIC WIRES
}

\author{
By John M. Miller
}

\section{CONTENTS}

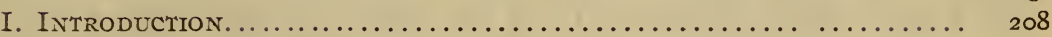

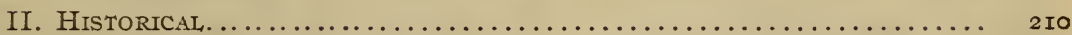

III. THEORETICAL. SELF-INDUCTANCE AND CIRCULAR MAGNETIZATION..... . 2 I2

I. Intensity of the electric field due to induction inside a straight

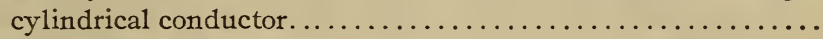

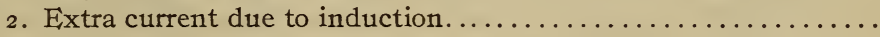

3. Definition of self-inductance for a circuit which contains iron...

4. External and internal inductance...................

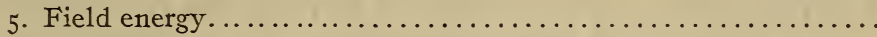

6. A comparison of electrical and magnetic quantities...........

7. Method of obtaining an exact permeability curve for circular magnetization of an iron wire.................... 216

IV. Experimental. Circular and axial magnetization.......... 2 I8

I. Determination of the permeability for circulat magnetization... 2 I8

2. Determination of the permeability for axial magnetization.... $22 \mathrm{I}$

3. Results and comparison of results. ................. 222

V. THEORETICAL. EFFECTIVE RESISTANCE AND INDUCTANCE......... 229

I. Effective resistance and inductance of straight cylindrical wires. . 229

2. Equivalent permeability of iron wires................. 230

3. Effective resistance and inductance of bimetallic wires........ $23^{\mathrm{I}}$

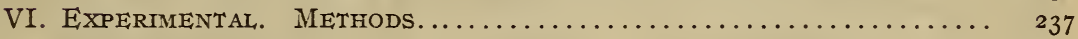

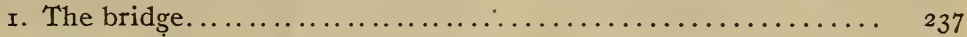

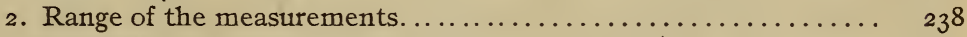

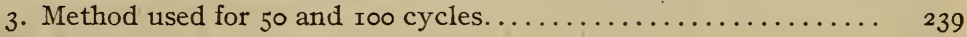

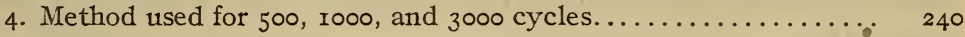

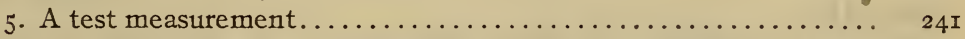

VII. THE EFFECTIVE RESISTANCE AND INDUCTANCE OF IRON WIRES ...... 242

I. Experimental results. . . . . . . . . . 242

2. Comparison of observed and computed values for zero current... 247

3. Equivalent permeability-Effects of hysteresis........... 248

VIII. THE EFFECTIVE RESISTANCE AND INDUCTANCE OF COPPER-STEEL BI-

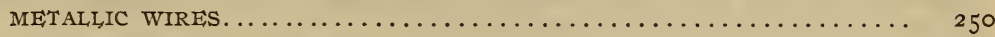

I. Experimental results.............................. 250

2. A comparison of observed and computed values............ 254

3. Effect of noncircularity of the core................. 257

IX. WirE TABLES. EFFECTIVE RESISTANCE AND INDUCTANCE OF COPPERSTEEL BIMETALLIC WIRES FOR SMALL CURRENTS ............ 260

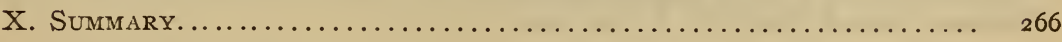

$\begin{array}{ll}10397^{\circ}-15-3 & 207\end{array}$ 


\section{INTRODUCTION}

When alternating current is flowing in a conductor the density and phase of the current will not be uniform over the cross section of the conductor. This is due to differences in impedance of the different paths of current-flow within the conductor, which become more pronounced the higher the frequency of the alternations. The effective resistance and inductance of the conductor as a whole will be different from the direct-current values and will depend upon the frequency. The effective resistance will increase and the inductance decrease with increasing frequency. This effect, frequently called the skin effect, is of interest from a purely scientific standpoint and is sometimes of importance in engineering practice.

When the conductor is of simple form and the permeability of the material is known and may be considered a constant, the effective resistance and inductance can be calculated in a number of cases. Formulas have been given for a straight cylindrical conductor, ${ }^{1}$ a concentric main, ${ }^{2}$ a tubular conductor, ${ }^{2}$ parallel wires, ${ }^{3}$ a circle, ${ }^{4}$ a single-layer coil, ${ }^{5}$ a stranded wire, ${ }^{6}$ a strip which is part of an infinite plane plate, ${ }^{7}$ and perhaps for other cases. When, however, the conductor is made up entirely or in part of ferromagnetic material and the magnetizing forces in that material are such that the permeability can not be considered a constant, the problem becomes so complex that a solution is apparently impossible. In such cases the changes in inductance and resistance are very large and depend not only upon the frequency but also upon the current strengith.

These two phases of the problem correspond to two uses of iron or bimetallic wires in practice-telephone and power transmission work. Conductors of iron or steel are used to some extent in

\footnotetext{
1 Maxwell, Elect. and Mag., II, 690. Heaviside, Elect. Papers, II, p. 64. Rayleigh, Phil. Mag., 21, p. 38I; 1886. Kelvin, Math. and Phys. Papers, III, p. 49 I.

2 Russell, Phil. Mag., 17, p. 524; I909.

3 Nicholson, Phil. Mag., 17, p. 255; and 18, p. 4r7; I909.

${ }_{4}^{4}$ Rosa and Grover, this Bulletin, 8, p. I8I; rgrr.

${ }^{5}$ M. Wien, Ann. d. Phys., 14, p. I; I904. Sommerfeld, Ann. d. Phys., 15, p. 673; I904. Picciati, Il Nuovo Cimento (5), 2, p. 35 r. Coffin, this Bulletin, 2, p. 275. Cohen, this Bulletin, 4, p. I6r.

${ }^{6}$ Lindemann, Jahrb. d. Drahtl. Tel., 4, p. 56r; I9I0-Ir.

7 Bethenod, Jahrb. d. Draht1. Tel., 2, p. 397; r909.
} 
telephone work where the currents are feeble and the magnetizing forces within the conductor are very small. It has been shown experimentally that for very small magnetizing forces the permeability of iron and steel is approximately constant. If we know this value of the permeability for the material and for the circular magnetization which results when a current flows through a wire, the values of the effective resistance and inductance for any frequency can be calculated by formulas which have been developed, provided the material is the same at all parts of the conductor. In this connection it is of interest to compare the permeability of iron wires when magnetized circularly, as when carrying a current, with the permeability for magnetization along the axis of the wire or axial permeability such as is ordinarily obtained in a magnetic measurement. In this paper the results of a number of such comparisons are given, and the method permits the exact permeability curves for circular magnetization to be obtained when the material of the wire is homogeneous throughout.

Conductors which are made up of two metals are used to some extent for telephone work. We will consider mainly the type of bimetallic wire which has a more or less circular core of steel surrounded by a shell of copper. The present paper deals with experimental determinations of the electrical properties of these wires up to and including telephone frequencies and develops formulas which, with some limitations, make it possible to compute the effective resistance and inductance of bimetallic wires at different frequencies.

Steel and bimetallic wires are also used for power-transmission purposes. Here the magnetizing forces in the conductor may be considerable and the resistance and inductance may be quite different from the values for feeble currents. In this work the effect of current strength upon the effective resistance and inductance of the conductors included in the investigation has also been studied experimentally and values of effective permeabilities of the materials have been computed and plotted in some cases. 


\section{HISTORICAL}

The amount of experimental work upon conductors made up of or containing iron is very great. Of these papers we shall review two which have more or less direct bearing upon the work in hand.

Klemenčič ${ }^{8}$ made measurements of the self-inductance of an annealed soft iron, a hard iron, and a Bessemer steel wire with direct current of different strengths. The wires were I $\mathrm{m}$ long and $2 \mathrm{~mm}$ in diameter. Essentially the method of measurement was to balance a resistance bridge which contained the iron wire in one arm and then read the ballistic deflection of the galvanometer when the current in the bridge was reversed. From the deflections the values of the self-inductance were determined and values of the susceptibility for circular magnetization computed, using a formula which holds only for constant susceptibility. Thus were obtained what may be called effective values of the susceptibility. Then arose the difficulty as to what values of the magnetizing force these values of the susceptibility corresponded. An average value was taken, which was obtained by summing up all of the values of the magnetizing force over the total cross section of the wire and then dividing by the cross section. Susceptibility curves were also determined for the same wires by the ordinary ballistic method, in which the magnetization was along the axis of the wire. The results of the two experiments were compared and the author concluded that in general the susceptibility is different in the circular and axial directions. The results of Klemenčič have been recomputed in part on the basis of developments outlined in the present paper and will be presented later.

Fowle, ${ }^{9}$ in a series of three papers, treats very thoroughly the electrical properties of compound or bimetallic wires.

The first paper gives a number of expressions for the ratios of the weight and conductance of a bimetallic wire to a solid copper conductor of the same size. It contains tables and curves of these ratios for copper-clad and aluminum-clad steel wires with different ratios of copper and aluminum content by cross section and weight.

8 Klemenčič, Wied. Annal., 53, p. 1053; 1894.

${ }^{9}$ Fowle, Elect. World, 56, pp. I471, I521, 1910; and 57, p. I08, I9Ix. 
The second paper is concerned with the distribution of current between core and shell in the above-mentioned wires as a function of the shell cross section and develops a somewhat complicated formula for the internal self-inductance per unit length of a compound wire. Now, the expression for the internal inductance per centimeter of length of a solid wire of one metal is very simply given by $\frac{\mu}{2}$ where $\mu$ is the permeability (constant). This inductance does not depend upon the size of the wire. It is interesting to note that also in the bimetallic wire the internal inductance is independent of the wire size. If the characteristics of the materials are the same from wire to wire, the inductance varies with the conductivity of the wire alone.

The author discusses the probable conductivity of the steel in bimetallic wires and gives simple formulas to calculate the inductance when the conductance ratio of steel to copper is I 2 per cent and steel to aluminum is 19.35 per cerit.

In the third paper the results of experiments upon Nos. 6, 8, 9, IO, I2, and I4, copper-clad wires are given. The resistances and temperature coefficients of resistance were measured, and the per cent conductivities relative to solid copper were computed. An attempt to determine the conductance ratio of the steel in the core was somewhat unsatisfactory, on account of the difficulty in measuring the cross section of the core accurately. The results seem to show a decreasing conductivity of the steel with decreasing size of wire.

The alternating current measurements gave the ratio of apparent to ohmic resiscances and the inductive reactances for currents ranging from 3 to 35 amperes and frequencies of 25, 40, and 60 cycles. The wires were strung in rectangular loops and with separations of $\mathrm{I} 2, \mathrm{I} 8$, and 24 inches between the long sides.

From the inductance measurements average values of the permeability of the core were computed for different separations, current strengths, and frequencies. The accuracy of these values is reduced by the fact that the internal inductance of the wire was a small part of the whole. 


\section{THEORETICAL. SELF-INDUCTANCE AND CIRCULAR MAGNETIZATION}

\section{INTENSITY OF THE ELECTRIC FIELD DUE TO INDUCTION INSIDE A STRAIGHT CYLINDRICAL CONDUCTOR}

Suppose a current of uniform distribution to flow through a homogeneous cylindrical conductor and return along the surface so that there is no field external to the conductor. If the strength

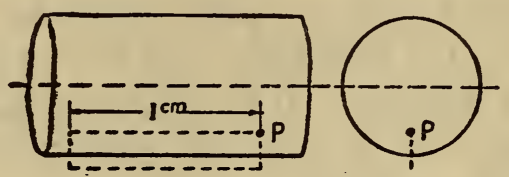

FIG. I

of the current in the conductor should change, we can determine the intensity of the electric field due to induction at any point $P$ (Fig. I) internal to the wire as follows: We have

$$
\int E d s=-\frac{d}{d t} \int B_{n} d S
$$

that is, the line integral of the field intensity around a closed path is equal to the rate of decrease with the time of the surface integral of the induction normal to a surface bounded by the closed curve. Integrating around the rectangular path shown in the figure, we get $\int E d s=E_{\mathrm{P}} \times \mathrm{I}$ where $E_{\mathrm{P}}$ is the field intensity at the point $P$. This is equal by the equation to the rate of change of the flux of induction through the rectangle, or since the induction is zero outside is equal to the rate of change of the induction between $P$ and the outside of the conductor. Hence the field intensity depends upon the rate of change of the flux of induction outside of the point.

\section{EXTRA CURRENT DUE TO INDUCTION}

Assume a conductor of radius $\rho$ and resistivity $\sigma$ and consider the magnetic induction only in the concentric cylindrical shell of radius $x$ and thickness $d x$ and that the total flux of induction per 
unit length is $\phi$. Suppose this induction to be reduced to zero. The field intensity at all points inside of $x$ would be

$$
E=-\frac{d \varphi}{d t}
$$

the current density

$$
i=\frac{E}{\sigma}=-\frac{\mathrm{I}}{\sigma} \frac{d \varphi}{d t}
$$

the total current

$$
I=\frac{\pi x^{2}}{\sigma} E=-\frac{\pi x^{2}}{\sigma} \frac{d \phi}{d t}
$$

and the total quantity

$$
\int_{0}^{\infty} I d t=\frac{\pi x^{2}}{\sigma} \varphi
$$

If this same flux of induction were outside of the wire the quantity $\frac{\pi \rho^{2}}{\sigma} \phi$ would flow. Hence the effect of induction inside the wire in contributing to the extra current of induction must.be weighted in the ratio of the area of the cross section cut by the induction in collapsing upon the axis to the total area. of cross section of the conductor.

\section{DEFINITION OF SELF-INDUCTANCE FOR A CIRCUIT WHICH CONTAINS IRON}

If there is a mutual inductance $M$ between two circuits (I) and (2) and a current $I_{1}$ in the first is interrupted the quantity of electricity which will flow in the circuit (2) due to induction will be $q=\frac{M I_{1}}{R_{2}}$ where $R_{2}$ is the resistance of the second circuit. We could define $M$ in terms of the quantity $q$. In a similar manner the self-inductance of a circuit can be defined in terms of the quantity of electricity which would flow, due to the induction linked with the circuit, if the current in the circuit were interrupted or reversed. If the circuit contains iron the inductance will depend upon the current.

Suppose the circuit to be carrying a current $I$ and by repeated reversals of this current the iron has been brought into a cyclic 
state. Then the self-inductance $L$ corresponding to the current $I$ is given by $q=\frac{I L}{R}$ where $R$ is the resistance of the circuit and $q$ is one-half of the quantity of electricity which flows due to induction when $I$ is reversed.

\section{EXTERNAL AND INTERNAL INDUCTANCE}

If the flux of induction is outside of the wire

$$
q=\frac{\mathrm{I}}{R} \int B d S=\frac{\varphi}{R}
$$

and $L=\frac{\varphi}{I}$, the flux per unit current.

If the induction is inside the wire we have for the flux of induction per unit length $\int_{0}^{\rho} B_{x} d x$. This is equivalent in its contribution to the extra current of induction to $\phi$ tubes of induction outside the wires where

$$
\boldsymbol{\varphi}=\int_{0}^{\rho} B_{x} \frac{x^{2}}{\rho^{2}} d x
$$

if the wire is homogeneous in respect to its conductivity.

Hence the internal inductance or that portion of the selfinductance which is due to the internal flux

$$
L_{\mathrm{i}}=\frac{\varphi}{I}=\frac{\mathrm{I}}{I} \int_{0}^{\rho} B_{x} \frac{x^{2}}{\rho^{2}} d x .
$$

\section{FIELD ENERGY}

If $d v$ is the element of volume of the wire, we have $d v=2 \pi \times d x$ for a unit of length

and

$$
2 \pi x H_{x}=4 \pi I \frac{x^{2}}{\rho^{2}} ; H_{x}=\frac{2 x I}{\rho^{2}} .
$$

Substituting these values in the above expression for $L_{\mathbf{i}}$, we have

$$
\frac{\mathrm{I}}{2} L_{i} I^{2}=\int \frac{B_{x} H_{x}}{8 \pi} d v=\frac{\mathrm{I}}{8 \pi} \int \mu_{x} H^{2}{ }_{x} d v
$$


where the integral is taken throughout the volume of the conductor. This is in the usual form of the expression for the electromagnetic energy in the field, but though the equation can be used to compute the inductance, neither side of the equation is energy unless $L_{\mathrm{i}}$ and $\mu$ are constants.

To show this, let us consider the case of a long solenoid of radius $r$ filled with perfectly soft homogeneous iron, and let the solenoid have one turn of conductor per centimeter of length. Let some source of energy start up a current in the solenoid. We will calculate the energy which must be supplied to a single turn to build up its share of the field, which evidently is for I $\mathrm{cm}$ of length of the solenoid. The emf of induction in this single turn is

$$
E=-\frac{d}{d t} \int B d S
$$

Since the magnetic intensity $H$ is constant over the cross section of the solenoid, $B$ is also constant and

$$
E=-\frac{d}{d t}\left[\pi r^{2} B\right]=-\pi r^{2} \frac{d B}{d t}
$$

The energy which goes into the field is

$W=-\int_{0}^{\infty} E I d t=\pi r^{2} \int_{0}^{\mathrm{B}_{f}} I d B$, writing the subscript $f$ for final values, but $H=4 \pi I$ and $B=\mu H$

Hence $W=\frac{r^{2}}{4} \int_{0}^{\mathrm{B} f} H d B=\frac{r^{2}}{4}\left[\int_{0}^{\mathrm{B}_{f}} \mu H d H+\int_{\mu_{o}}^{\mu_{f}} H^{2} d \mu\right]$

The values of the integrals depend upon $\mu$ as a function of $H$, hence the energy is not determined unless this function is specified. If $\mu=$ constant, then $W=\frac{\mu_{f} H^{2}{ }_{f} r^{2}}{\mathrm{~S}}=\frac{\mathrm{I}}{8 \pi} \int \mu_{f} H^{2} f d v$, and we have the ordinary expression for the energy.

- In any case

$$
L=\frac{\int B d S}{I}=\frac{\mu_{f} H_{f} \pi r^{2}}{I}
$$

and since $H=\Delta \pi I ; \frac{\mathrm{I}}{2} L I^{2}=\frac{\mu_{f} H^{2}{ }_{f} \gamma^{2}}{8}=\frac{\mathrm{I}}{8 \pi} \int \mu_{f} H^{2}{ }_{f} d v$. 
The latter is only an energy equation when $\mu$ is a constant. We may apply this equation when the iron shows hysteresis if we consider it to be in a cyclic state and $\mu$ to be the ratio of $B$ to $H$, corresponding to the tip of the hysteresis loop.

\section{A COMPARISON OF ELECTRICAL AND MAGNETIC QUANTITIES}

The current $I$ is related to the magnetic intensity $H$ by means of a line integral. Our definition of the self-inductance $L$ in terms of quantity of electricity has as a consequence that $I L$ is related to the magnetic induction $B$ through a surface integral. Therefore $L$ per unit length is related to $\mu$. Also $L I^{2}$ is related to $\mu H^{2}$ through a volume integral, as has been shown in the preceding section.

\section{METHOD OF OBTAINING AN EXACT PERMEABILITY CURVE FOR CIR- CULAR MAGNETIZATION OF AN IRON WIRE}

Suppose a current $I$ to be flowing in a homogeneous iron wire of radius $\rho$ and that the iron is in a cyclic state. The self-inductance of the wire is given by $\frac{\mathrm{I}}{2} L I^{2}=\frac{\mathrm{I}}{8 \pi} \int \mu H^{2} d v$. Let us consider only the internal inductance per unit length and write it $L_{i}$.

Then $\frac{\mathrm{I}}{2} L_{i} I^{2}=\frac{\mathrm{I}}{8 \pi} \int_{0}^{\rho} \mu H^{2} 2 \pi x d x$ where $d x$ is an element of the radius at a distance $x$ from the axis.

Since $2 \pi x H=4 \pi \frac{I x^{2}}{\rho^{2}} ; H=\frac{2 I x}{\rho^{2}} ; x=\frac{\rho^{2} H}{2 I} ; d x=\frac{\rho^{2} d H}{2 I}$ and $L_{i}=\frac{2}{I^{2}} \frac{\mathrm{I}}{8 \pi} \int_{0}^{\frac{2 I}{\rho}} \mu H^{2} \cdot 2 \pi \frac{\rho^{2} H}{2 I} \cdot \rho^{2} \frac{d H}{2 I}=\frac{\rho^{4}}{8 I^{4}} \int_{0}^{\frac{2 I}{\rho}} \mu H^{3} d H$

If the current in the wire is increased to $I+\Delta I$ and the iron again brought into a cyclic state, the self-inductance will then be $L_{i}+\Delta L_{i}=\frac{\rho^{4}}{8(I+\Delta I)^{4}} \int_{0}^{\frac{2(I+\Delta I)}{\rho}} \mu H^{3} d H$, which, since the iron is homogeneous

$$
\begin{gathered}
=\frac{\rho^{4}}{\delta(I+\Delta I)^{4}} \int_{0}^{\frac{2 I}{\rho}} \mu H^{3} d H+\frac{\rho^{4}}{8(I+\Delta I)^{4}} \int_{\frac{2 I}{\rho}}^{\frac{2(I+\Delta I)}{\rho}} \mu H^{3} d H \\
=L_{i}\left(\frac{I}{I+\Delta I}\right)^{4}+\frac{\rho^{4}}{8(I+\Delta I)^{4}} \int_{\frac{2 I}{\rho}}^{\frac{2(I+\Delta I)}{\rho}} \mu H^{3} d H
\end{gathered}
$$


This may be interpreted as follows: That by increasing the current those tubes of induction present in the earlier case have been crowded in toward the axis tending to diminish the inductance in the ratio of $\mathrm{I}:\left(\frac{I}{I+\Delta I}\right)^{4}$ and a new flux of induction has been added in the outside shell where the value of $H$ varies from $\frac{2 I}{\rho}$ to $\frac{2(I+\Delta I)}{\rho}$ and which tends to increase the inductance by the amount given in the second term on the right.

Now let us assume $\mu$ to have the uniform value $\mu_{\rho}$ in the outside shell over which the integral is taken. Then

and

$$
L_{i}+\Delta L_{i}=L_{i}\left(\frac{I}{I+\Delta I}\right)^{4}+\frac{\mu_{\rho} \rho^{4}}{8(I+\Delta I)^{4}} \cdot \frac{\mathrm{I} 6}{4 \rho^{4}}\left[(I+\Delta I)^{4}-I^{4}\right]
$$

$$
\Delta L_{i}=\left[L_{i}-\frac{\mu_{\rho}}{2}\right]\left[\frac{I^{4}}{(I+\Delta I)^{4}}-\mathrm{I}\right]=\left[L_{i}-\frac{\mu_{\rho}}{2}\right]\left[-4 \frac{\Delta I}{I}\right]
$$

neglecting terms in higher powers of $\frac{\Delta I}{I}$

Hence $\mu_{\rho}=2 L_{i}+\frac{I}{2} \frac{\Delta L_{i}}{\Delta I}$

and in the limit when $\Delta I$ and $\Delta L_{i}$ become $d I$ and $d L_{\imath}$

(2) $\mu_{\rho}=2 L_{i}+\frac{I}{2} I \frac{d L_{i}}{d I}$

Where $\mu_{\rho}$ is the value of $\mu$ corresponding to the magnetizing force $H=\frac{2 I}{\rho}$. For $\mu=\mu_{\rho}$ a constant, $\frac{d L_{i}}{d I}=o$ and we have $L_{i}=\frac{\mu}{2}$ which is the ordinary expression for the internal inductance per centimeter of length when the permeability is constant. If we have determined a curve by direct current which gives $L_{i}$ as a function of $I$, we can, from the values of $L_{i}$ and $\frac{d L_{i}}{d I}$ at different points of the curve, determine a curve for $\mu$ as a function of $H$. 


\section{EXPERIMENTAL. CIRCULAR AND AXIAL MAGNETIZA- TION}

\section{DETERMINATION OF THE PERMEABLITY FOR CIRCULAR MAGNETIZATION}

In determining $L_{i}$ as a function of $I$ an Anderson bridge was used, as shown in Fig. 2, with a secohmeter to alternately reverse the battery and galvanometer connections to the bridge. Referring to the figure, $P$ and $R$ were Io-ohm coils in oil; $C$, mica condensers of about 3 microfarads capacity; $r$ was made up of two resistance boxes, one of which was variable from tenths to thousandths of an ohm and the other contained larger valued coils; $S$

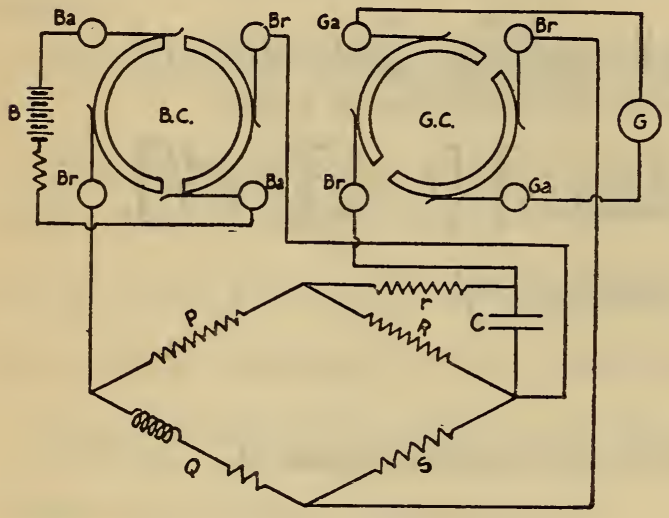

FIG. 2.-Secohmeter and bridge was a special box of current carrying coils in oil in which the resistance could be varied in steps of onethirtieth of an ohm from 0.033 to $0.767 \mathrm{ohm}$. The $Q$ arm contained the iron wire to be measured or a substitute copper wire of the same length, a small inductance for ballast, several manganin or copper links of the same length and same size wire and a mercury slider. ${ }^{10}$ The latter was used in getting a resistance balance and has the advantage that the change in inductance with the setting is extremely small-less than $20 \mathrm{~cm}$ for the whole range, which is about o. I ohm. To reduce the heating it was, in general, partially submerged in water. The total current in the bridge was read by an ammeter in series with the battery. Currents as high as ro amperes were used in the measurements. The bridge is balanced for inductance when the total quantity of electricity which flows through the galvanometer due to a reversal of the battery current is zero. The condition for balance is $L=C S(R+2 r)$ when $P=R$ and $Q=S$.

${ }^{10}$ Dellinger, Phys. Rev., 32, p. 614, 191r; and, 33, p. 215, 19r1. Grover and Curtis, this Bulletin,8, p. $466 ; 1912$. 
A method of differences was used in making the measurements. First a copper wire was put in the $Q$ arm and a resistance balance obtained by means of the manganin links and mercury slider; then the secohmeter was run and an inductance balance obtained by means of the resistance $r$. This was in effect a zero balance for the bridge. The iron wire was then substituted for the copper and a resistance balance obtained by the mercury slider alone or by subsituting copper links for manganin links to bring the balance within the range of the mercury slider. Then a series of inductance balances were obtained by means of $r$ with increasing currents in the bridge and between these balances the resistance balance was adjusted. The zero balance for the bridge was then again obtained. The difference in inductance of the iron and copper wires was then given by $\Delta L=2 C S \Delta r$ where $\Delta r$ is the difference in the setting of $r$ with the iron wire in and out. The difference between the external inductance for the iron and copper wires was computed and applied as a correction, which then gave the internal inductance of the iron wire less one-half a centimeter of indictance per centimeter of length.

In the earlier work the bridge was so arranged that it was necessary to bend the wire into a rectangle in order to introduce it into the bridge. In order to eliminate the working of the iron caused by the bending, the bridge was modified so that straight wire up to $140 \mathrm{~cm}$ in length could be used. The wires were soldered into copper terminals which dipped into mercury cups. A heavy copper wire of the same length and with similar terminals was used in determining the zero balance of the bridge. While being measured the wires were immersed in oil in a long wooden tank, in order to reduce the drift due to temperature changes. The leads which connected to the bridge were run perpendicularly to the wire under measurement for a distance of $20 \mathrm{~cm}$. Then one of these leads ran parallel to. meet the other, and the two were run side by side about $2 \mathrm{~m}$ to the bridge.

In order to get accurate results and a steady balance of the bridge, considerable care was necessary in the adjustment and manipulation of the secohmeter. In the first place it was found necessary to keep the commutator segments and brushes very 
clean and polished and generously oiled with a light oil, such as sewing-machine or clock oil. On account of the high currents used a frequent overhauling was essential to good operation. Secondly, it was found to be very important that the brushes should be so adjusted that the reversal of the galvanometer connections came very exactly midway between the reversals of the battery connections. The result of this adjustment is to eliminate to a great extent effects upon the inductance balance due to a lack of balance of the bridge for resistance. It was of special importance in this work, for when high-current strengths were used the bridge was extremely sensitive with respect to a resistance balance and the heating in the $Q$ arm, which was made up in good part of metals with high-temperature coefficients, made it practically impossible to preserve a balance. The adjustment of the secohmeter was accomplished by substituting a.dry cell for the battery, a less sensitive galvanometer for the galvanometer used in the measurements, and, in place of the bridge, connecting wires across from the $\mathrm{Br}$ terminals on one side to those on the other. The brush holder on the galvanometer commutator was then adjusted, so that when the secohmeter was running the galvanometer showed no deflection in either direction. With the secohmeter adjusted in this manner the resistance balance of the bridge could be disturbed so as to deflect the galvanometer off the scale without producing an appreciable effect upon the inductance balance.

The secohmeter was run by a small shunt motor and the speed could be regulated by a variable resistance in the armature circuit. The effect of the speed upon the balance was investigated and it was kept so low that a considerable increase produced no appreciable change in the balance. At different times from 13 to 30 reversals per second were used.

In order to obtain consistent results for circular magnetization, it was found to be necessary to demagnetize the iron wire carefully just as is necessary in measurements of axial magnetization. This is illustrated in the curves in Fig. 3, which show two sets of determinations of $L_{\mathrm{i}}$ as a function of $I$ for a soft-iron wire (No. 43 Steel Wire Gage). The first set was taken without any attempt to 
demagnetize the wire, and the results are plotted by closed circles. Before taking the next set the wire was demagnetized by reducing the current in the wire slowly from 4 amperes to o.I ampere with the secohmeter running. The results of the second set are plotted by open circles. The curves show the same characteristics as the induction curves obtained by Burrows ${ }^{11}$ in investigating the effect of imperfect demagnetization in ordinary magnetic measurements; i. e., considerably higher values of the magnetic induction for the demagnetized wire in the region where the curve is steep, but

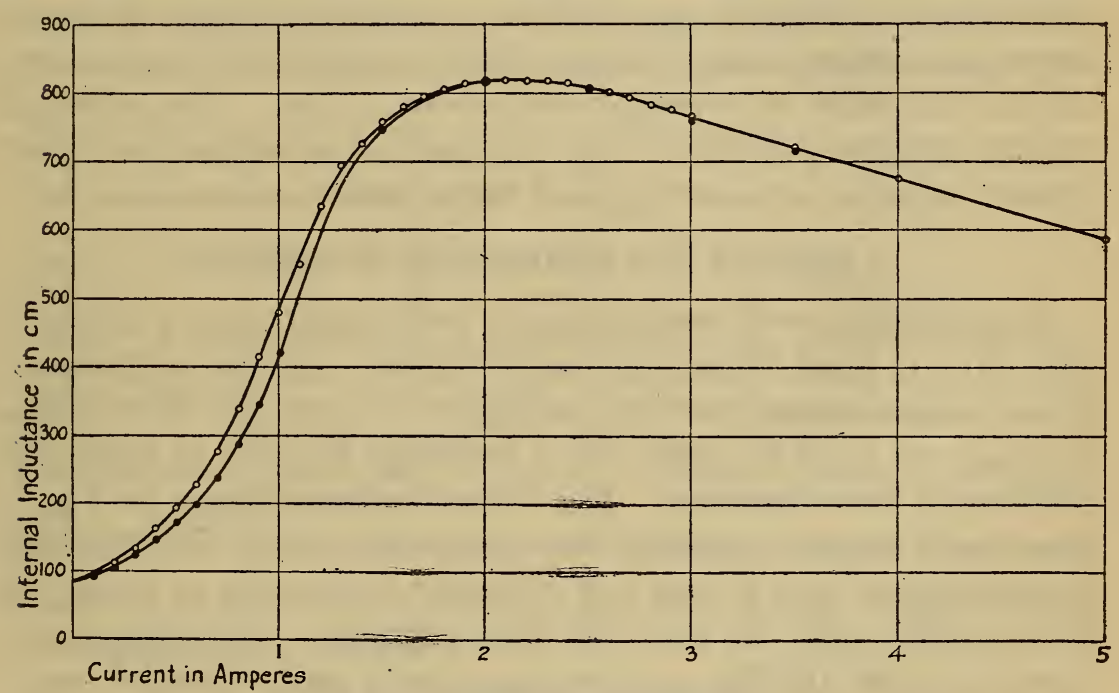

FIG. 3.-Effect of demagnetization

practically no difference in the values after the knee of the curve is reached.

Having obtained a curve for $L_{i}$, tangents to the curve were drawn at a number of points and values of $\frac{d L_{\mathbf{i}}}{d I}$ determined. Then $\mu$ was calculated from equation (2) and plotted as a function of $H$.

\section{DETERMINATION OF THE PERMEABILITY FOR AXIAL MAGNETIZATION}

In order to compare the permeability for circular magnetization with that obtained when the wires were magnetized axially, measurements were also made upon the wires by the ordinary ballistic 
method. ${ }^{12}$ The wires were a meter or more in length and the magnetizing coil was I I $5 \mathrm{~cm}$ long and $2.6 \mathrm{~cm}$ in diameter, with eight turns to the centimeter. The test coil had a single layer of 1000 turns of No. 32 enameled wire wound on a glass tube and was about $22 \mathrm{~cm}$ long. The galvanometer was standardized by means of a variable mutual inductance, whose secondary was always kept in the circuit. Deflections were obtained with the iron wire in the test coil and with the test coil alone, and this data, together with the diameter of the wire and the sensitivity of the galvanometer, sufficed to compute $\mu$. In the circular measurements an average value over the whole length of wire is obtained, and in the axial an average over about $22 \mathrm{~cm}$. The effect of having different portions of the wire inside the test coil was tried without showing a marked lack of homogeneity in any case.

\section{RESULTS AND COMPARISON OF RESULTS}

In the earlier work measurements were made upon a soft-iron wire (No. 43 Steel Wire Gage) and drill rod $1 \mathrm{I} / 2 \mathrm{~mm}$ in diameter. These measurements were not satisfactory. At this time it was necessary to bend the wire into a rectangle in order to make the inductance measurements. The determinations shown in Fig. 3 were made before a method was determined upon for the axial measurements, and it was not considered desirable to bend the wire straight again for the axial measurements. The other measurements upon the No. 43 wire were made upon annealed specimens; the process of annealing was faulty and the wires showed considerable scale. The measurements upon the drill rod and the recomputed results of Klemenčič ${ }^{12 a}$ for an annealed soft-iron wire are shown in Figs. 4 and 5. Klemenčič gives two series of axial measurements taken before and after the circular determination. It was necessary in this work to bend the wire to introduce it into the bridge, and the differences between the two series of axial measurements may possibly be due to the bending. These curves show marked differences between the permeabilities for circular and axial magnetization. The circular permeability is lower, and

12 The author is indebted to Dr. C. W. Burrows for suggestions with respect to this work. 12a See p. 21 . 
as is more definite in Fig. 4, the maximum comes at a higher magnetizing force. These characteristics are repeated in some of the later curves.

After this the bridge was so arranged that straight pieces of wire could be used. Samples of ungalvanized commercial iron telegraph and telephone wires were then obtained. ${ }^{13}$ Axial permeability curves were determined for a No. 4 , a No. 8, and a No. Io of each of the three grades known as E. B. B. (Extra Best Best), B. B. (Best Best), and S. (Steel). (The diameters of the wires accorded with the Birmingham Wire Gage, excepting for the No. 4 B. B. and No. 4 Steel, which agreed better with the Steel Wire

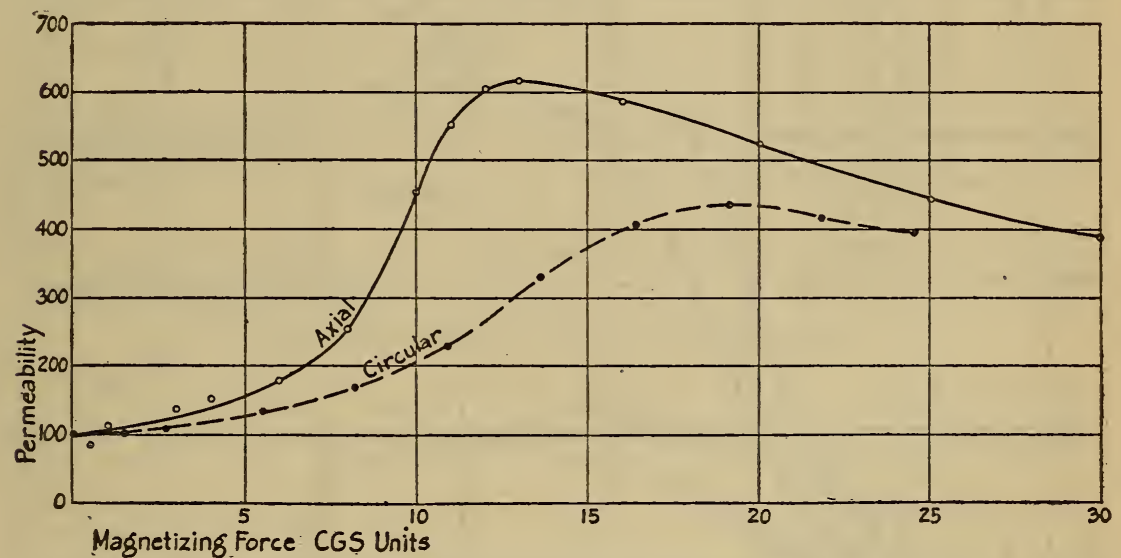

Fig. 4.-Permeability curves for drill rod

Gage.) These curves are shown in Fig. 6. The wires of the same grade show similar magnetic characteristics, with the exception of No. ro B. B. Another piece from the same coil of this latter wire gave a similar curve. In the later work the six samples of the E. B. B. and S. grades were used, since they represented the extremes in magnetic characteristics. In Figs. 7, 8, and 9 are given the curves for both axial and circular permeabilities. Two sets of curves are given for No. 4 E. B. B. (Fig. 7). The set marked (I) shows the characteristics of the wire in its original condition. It will be noted that there is a very great difference

${ }^{13}$ Kindly furnished by C. L. Miller, of the American Steel \& Wire Co.

$10397^{\circ}-15-4$ 
between the axial and circular curves for No. 4 E. B. B. and No. 4 S., while No. 8 E. B. B. and No. 8 S. and also No. Io S. show a fair agreement between the two permeabilities. No. Io E. B. B. reaches a somewhat higher maximum for the circular magnetization and it comes at a higher magnetizing force. With the exception of No. 4 E. B. B., the values for minimum permeability show a close agreement.

The differences are undoubtedly due to nonhomogeneity caused either by drawing the wire or heat treatment. In the axial meas-

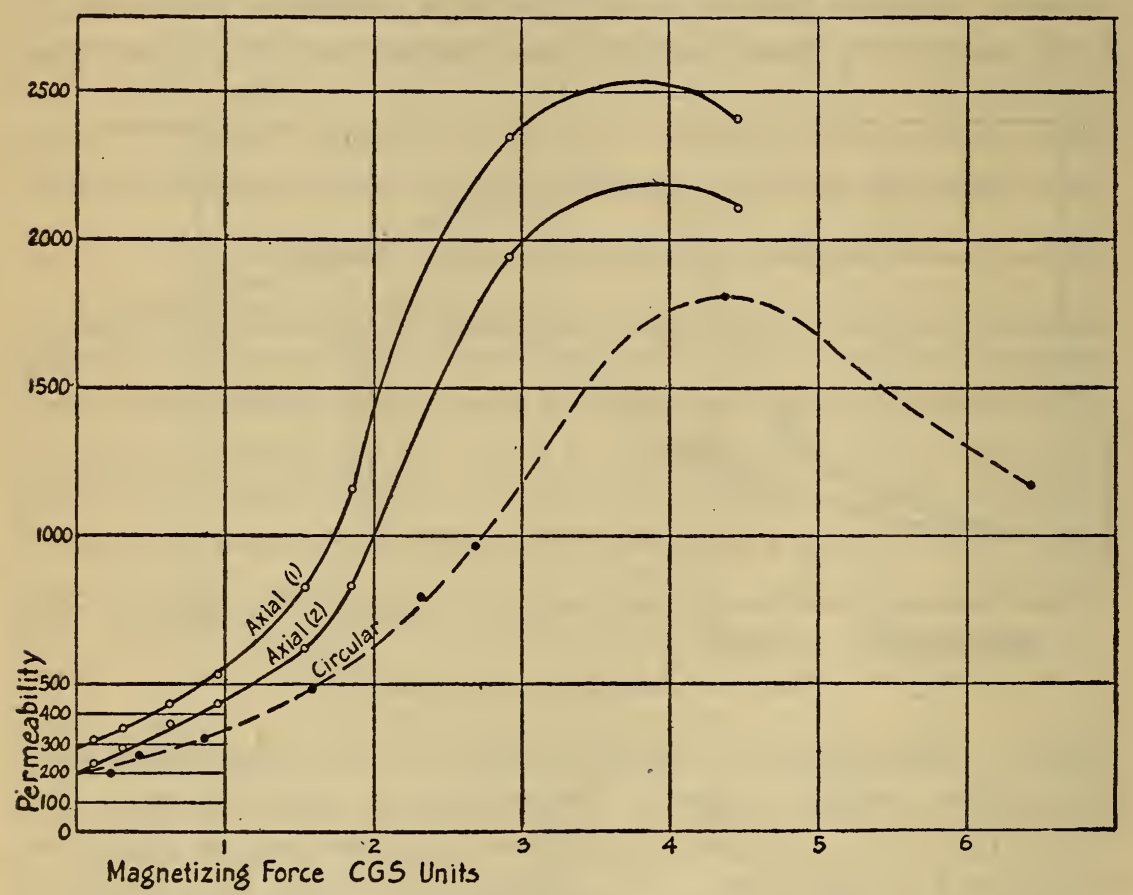

FIG. 5.-Annealed soft iron wire. Klemenčič

urement an average value of the magnetic flux over the whole cross section is obtained and each portion is subjected to the same magnetizing force. In the circular measurement the flux is weighted in its effect upon the self-inductance in proportion to the area of the cross section which it surrounds; for this reason the flux at the outside of the wire is more important. Also the magnetizing force is highest at the outside of the wire. If a wire 


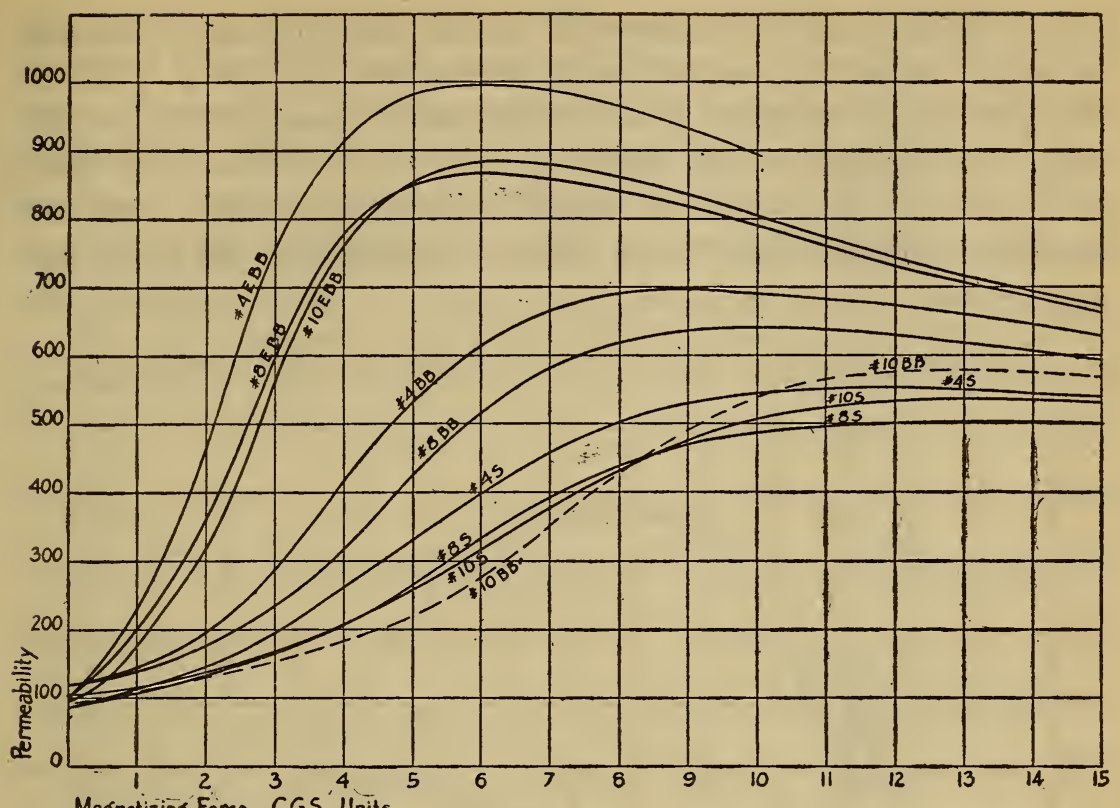

Magnetizing force CGS_Units

FIG. 6.-Axial permeability. Iron telephone wires

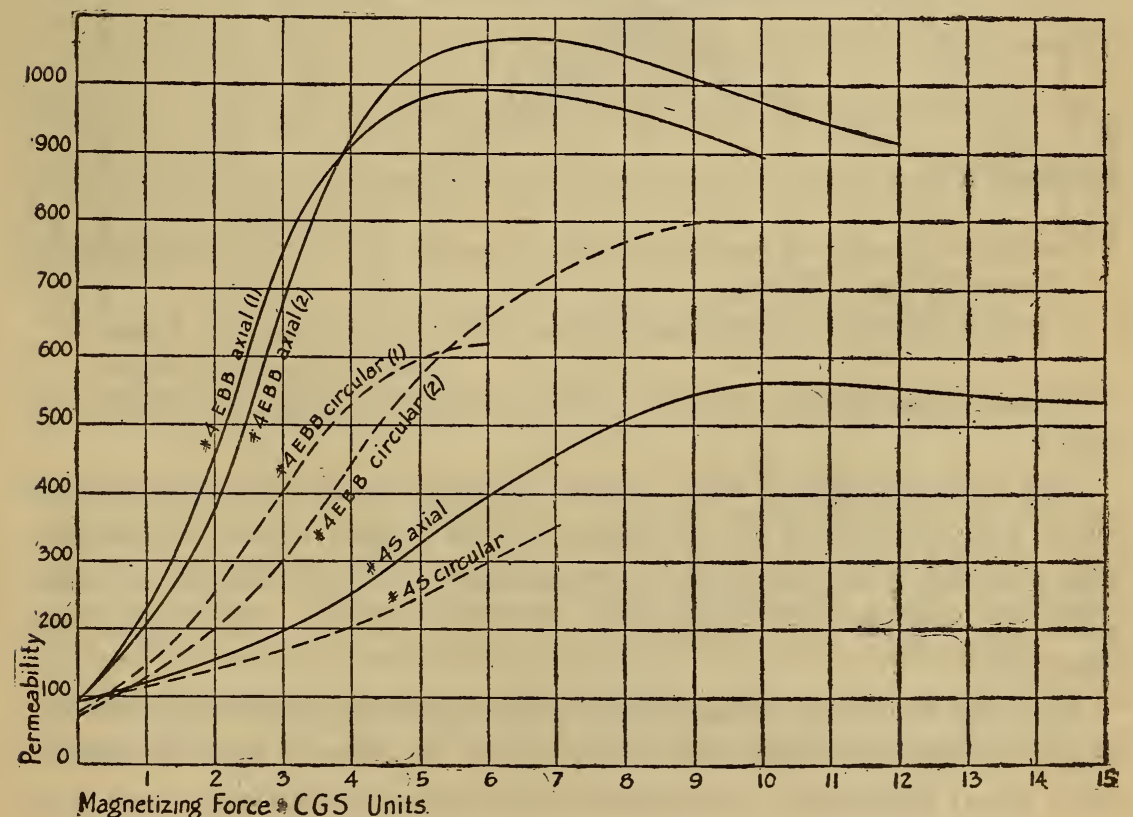

FIg. 7.-Circular and axial permeabilities. No. 4 E. B. B. and No. 4 Steel 
had an outside shell of somewhat harder (magnetically) material we might expect a behavior such as is shown by No. 8 E. B. B. The axial curve would be lowered somewhat throughout the whole range on account of the harder portion, the circular still more influenced in the region of lower magnetizing forces, and the maximum might come at a higher magnetizing force; for the magnetizing forces as plotted are those at the outside of the

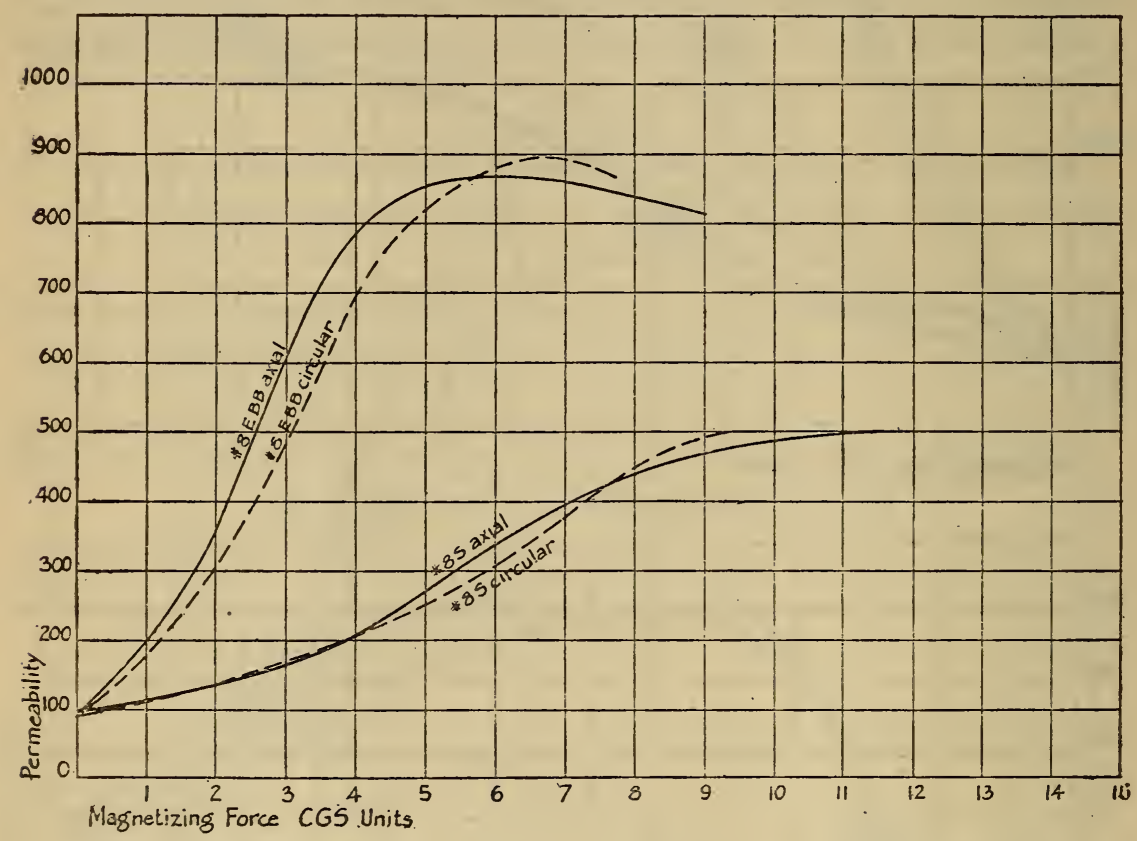

FIG. 8.-Circular and axial permeabilities. No. 8 E. B. B. and No. 8 Steel

wire and the softer material within would reach its maximum later.

The drawing of the wire would probably tend to lower the circular values relative to the axial. It is found, even in annealed transformer iron, that the permeability of the material is considerably higher in the direction of rolling thain in the transverse direction.

In order to obtain some further light upon the difference between the two permeabilities, the No. 4 E. B. B. wire, which showed a very great difference, was turned down from about $6 \mathrm{~mm}$ to $4 \mathrm{~mm}$ 
in diameter. The curves then obtained are those numbered (2) in Fig. 7. The differences were still great. Lower permeabilities were obtained in the steep portion of the curve for both magnetizations; both maxima came later and gave considerably higher values. No explanation for this behavior is at hand and further work in the direction of obtaining an explanation was not attempted.

For the purpose of obtaining information with respect to the permeability characteristics of the core of a copper-steel bimetallic

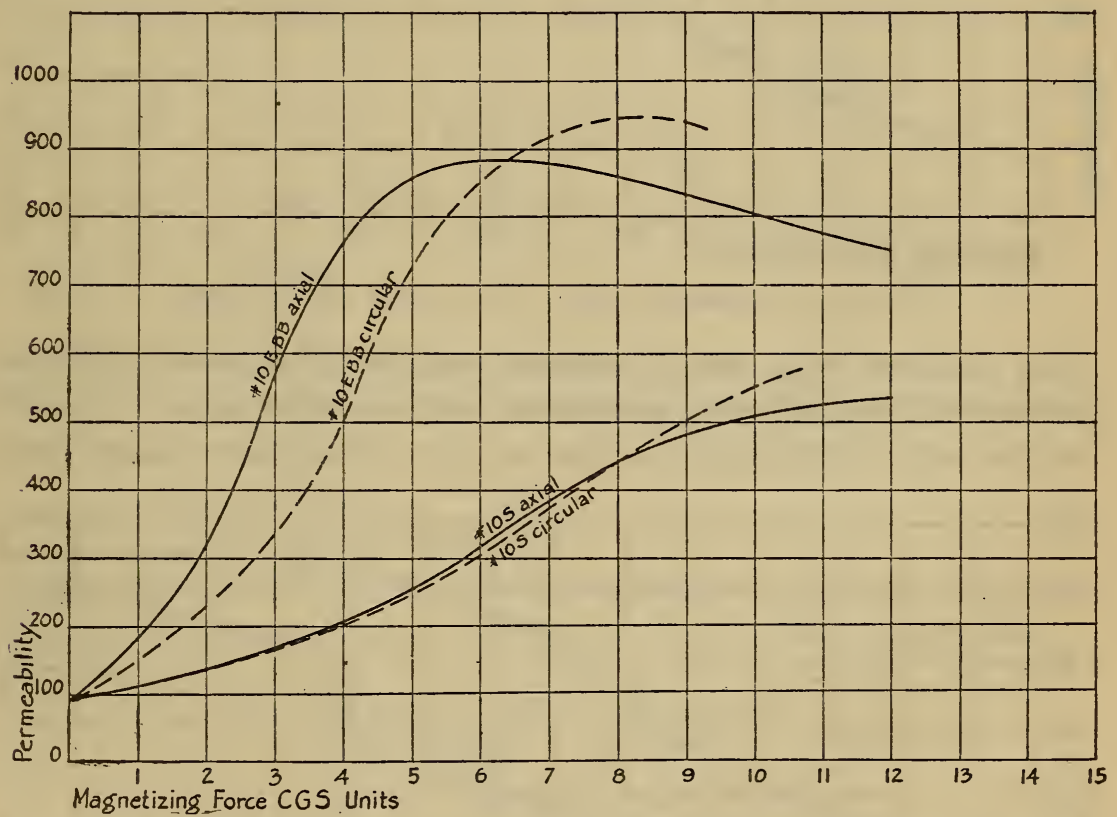

FIG. 9.-Circular and axial permeabilities. No. Io E. B. B. and No. Io Steel

wire, a No. 4 wire of this kind was turned down so as to give a steel wire of $2.5 \mathrm{~mm}$ diameter. It was expected that on account of the protecting coat of copper, the steel within might be more homogeneous. The curves for the circular and axial permeabilities (Fig. ro) do show a fair agreement of the two quantities. The working due to turning down the wire must, of course, produce some effect. In Fig. I I are given curves of the permeability for 
axial magnetization of the cores of No. 4, No. 8, and No. ro (A. W. G.) copper-steel wires. ${ }^{14}$ The curve for the No. 4 wire is the same as that in Fig. Io; the va'ues for the No. 8 and No. Io

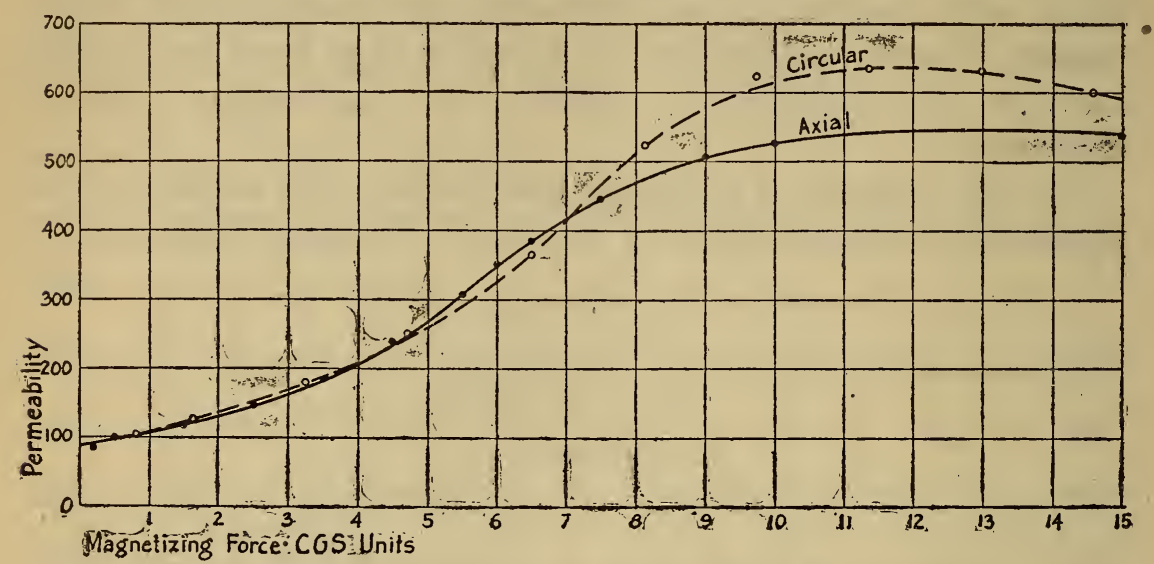

FIG. I0.-Permeability curves. Steel core of bimetallic wire

were obtained from measurements upon the whole wire, the cross section of the steel being computed from electrical data. In each of the latter determinations two samples, which were taken from

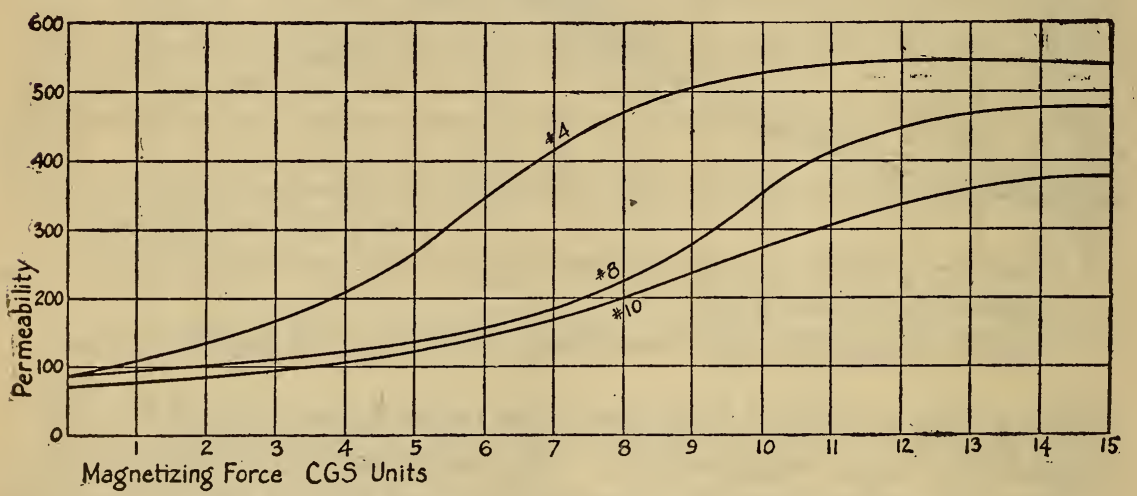

FIG. II.-Axial permeability. Steel cores of bimetallic wires

the ends of a 30-meter stretch of wire, gave close agreement. As might be expected, the permeabilities were lower for the smaller wires. 


\section{THEORETICAL. EFFECTIVE RESISTANCE AND INDUCTANCE}

\section{EFFECTIVE RESISTANCE AND INDUCTANCE OF STRAIGHT CYLINDRI- CAL WIRES}

As has been mentioned before, the problem of the effective resistance and inductance of straight cylindrical wires has been worked out for the case of constant permeability. The formulas generally used are those given by Kelvin, which make use of the ber and bei functions and their derivatives ber' and bei'. These functions introduced by Kelvin are given by the following series:

$$
\begin{aligned}
& \text { ber } x=\mathrm{I}-\frac{x^{4}}{2^{2} 4^{2}}+\frac{x^{8}}{2^{2} 4^{2} 6^{2} 8^{2}}-\cdots \ldots \\
& \text { bei } x=\frac{x^{2}}{2^{2}}-\frac{x^{6}}{2^{2} 4^{2} 6^{2}}+\frac{x^{10}}{2^{2} 4^{2} 6^{2} 8^{2} \mathrm{IO}^{2}}-\cdots \cdots
\end{aligned}
$$

where $x=2 \rho \sqrt{\frac{\pi p \mu}{\sigma}}$

and $\rho=$ radius of conductor in $\mathrm{cm}$.

$\sigma=$ resistivity of the material in absolute electromagnetic units.

$\mu=$ permeability.

$p=2 \pi$ times the frequency.

The formulas for the effective resistance and inductance can be put in simple forms by the use of the auxiliary quantities

$$
\begin{aligned}
& W=\text { ber } x \operatorname{bei}^{\prime} x-\text { bei } x \operatorname{ber}^{\prime} x \\
& Y=\left(\operatorname{ber}^{\prime} x\right)^{2}+\left(\operatorname{bei}^{\prime} x\right)^{2} \\
& Z=\operatorname{ber} x \operatorname{ber}^{\prime} x+\operatorname{bei} x \operatorname{bei}^{\prime} x
\end{aligned}
$$

We have then for the resistance $R^{\prime}$ at a frequency $f=\frac{p}{2 \pi}$ in terms of the direct current resistance

$$
R^{\prime}=R\left(\frac{x}{2} \frac{W}{Y}\right)
$$

and similarly for the internal inductance

$$
L^{\prime}=L\left(\frac{4}{x} \frac{Z}{Y}\right)
$$


in which $L$, the internal inductance for direct current and length $l$, is given by

$$
L=\frac{l \mu}{2}
$$

The tables of $\frac{x}{2} \frac{W}{Y}$ and $\frac{4}{x} \frac{Z}{Y}$ as given by Rosa and Grover ${ }^{15}$ have been of very great use in the present work.

\section{EQUIVALENT PERMEABILITY OF IRON WIRES}

If the material of the wire is homogeneous and the value of the initial permeability is known, we can calculate the effective resistance and inductance of solid iron wires by means of equations (3) and (4) for the case when the current in the wire is very small. The same formulas may be used to determine what may be called the equivalent permeability of the wire from experimental determinations of the effective resistance and inductance with considerable currents. By equivalent permeability is meant that value of the permeability which, if constant, would result for a given wire and frequency in the same value of effective resistance or inductance as that observed.

The equivalent permeability is quite readily computed from the resistance observations; for the ratio of the effective resistance to the direct current resistance gives the quantity $\frac{x}{2} \frac{W}{\bar{Y}}$ in (3) directly. From the above-mentioned tables we can then obtain the corresponding value of $x$ and then the equivalent permeability $\mu^{\prime}$. The computation from the internal inductance values is not as direct, for here the direct current inductance as well as the quantity $\frac{4}{x} \frac{Z}{Y}$ in (4) are functions of $\mu^{\prime}$. The following method was used to obtain $\mu^{\prime}$ from the inductance values: A series of values of $\mu^{\prime}$ was assumed and a table of the corresponding values of the inductance for a given frequency was computed together with the second and third differences. Then from the measured values of the inductance at that frequency the corresponding value of $\mu^{\prime}$ was obtained by interpolation.

15 Formulas and Tables for the Calculation of Mrutual and Self-Inductance (Revised) this Bulletin, 8 , p. 226; IgII (Scientific Paper No. I69). 
3. EFFECTIVE RESISTANCE AND INDUCTANCE OF BIMETALLIC WIRES

A simple method of computing the effective resistance and inductance of bimetallic wires over a considerable range of frequencies was developed from the consideration of two circuits in parallel. We will consider the copper-steel wire and assume the steel core to be circular in cross section and concentric with the shell. The magnetizing forces in the steel will be assumed so low that the permeability of the material is practically constant and equal to the initial value. Even for direct current most of the current flows in the high conductivity material of the shell and the magnetizing forces in the steel are relatively low. As the frequency increases the concentration of current in the shell also increases, and the effective resistance and inductance of the conductor become independent of the current strength. The assumption is also made that the distribution of the current in the shell is uniform at all frequencies. This would introduce appreciable error at high frequencies, but since the changes in distribution are small for a thin tube, the formulas are quite accurate in general up to telephone frequencies and over the range of frequencies wherein the changes are characteristic of the bimetallic wire. A check calculation upon a solid copper conductor will be given later. This serves to furnish an estimate of the error consequent upon the above assumption.

If we consider the magnetic fields of the core and shell separately, the total internal inductance of a bimetallic wire can be resolved into the following elements:

Inductive $\left\{\begin{array}{l}\text { (a) the flux in core due to core current } \\ \text { (b) the flux in shell due to core current } \\ \text { (c) the flux in shell due to shell current }\end{array}\right\}$ cutting 
The elements in (a), (b), and (c) belong to the total inductive effect upon the core and similarly (d) and (e) belong to the shell. We may designate them as self and mutual inductances in the following manner:

(a) + (b) $=L^{\prime}{ }_{1}+L^{\prime \prime}{ }_{1}=L_{1}=$ self-inductance of the core.

(c) $=M_{2,1}=$ mutual inductance of the shell on the core.

(d) $=L_{2}=$ self-inductance of the shell.

(e) $=M_{1,2}=$ mutual inductance, core on shell.

In computing the values of these elements, when the flux lies within the cross section of that part of the conductor upon which its inductive effect is being considered, it must be weighted in the integration in the proportion of the area of the conductor cut by the flux to the total area. Expressions for several, if not all, of these quantities have been given in other places, but they are derived here for the sake of completeness.

In the following $r_{1}$ is the radius of the core which has a permeability $\mu, r_{2}$ is the outside radius of the shell of permeability unity, and $x$ is the distance from the axis of a cylindrical shell of thickness $d x$. $\quad H_{1}$ and $H_{2}$ are the magnetic intensities due, respectively, to the currents $I_{1}$ in the core and $I_{2}$ in the shell. Their values are determined from the fact that the lines of force are circles concentric with the axis of the conductor and lie in a plane perpendicular to the axis, and the law that the integral of the magnetic intensity around such a line of force is equal to $4 \pi$ times the current flowing through the surface bounded by the line. The expressions are then derived for unit length as follows:

(a) $H_{1}=\frac{2 I_{1} x \text {. }}{r_{1}{ }^{2}}$ Weighting the flux in proportion to the area of the core cut $I_{1} L^{\prime}{ }_{1}=\mu \int r^{r^{1}}\left(\frac{2 I_{1} x}{r_{1}{ }^{2}}\right) \frac{x^{2}}{r_{1}{ }^{2}} d x=I_{1} \frac{\mu}{2} ; L^{\prime}{ }_{1}=\frac{\mu}{2}$ the familiar 
Miller]

expression for the internal self-inductance per $\mathrm{cm}$ of length.

(b)

$$
\begin{aligned}
H_{1} & =\frac{2 I_{1}}{x} \\
I_{1} L_{1}^{\prime \prime} & =\int_{r_{1}}^{r_{2}} \frac{2 I_{1} d x}{x}=2 I_{1} \log \frac{r_{2}}{r_{1}} \\
L_{1}^{\prime \prime} & =2 \log \frac{r_{2}}{r^{1}} ; L_{1}=L_{1}^{\prime}+L_{1}^{\prime \prime}=\frac{\mu}{2}+2 \log \frac{r_{2}}{r^{1}} \\
H_{2} & =\frac{2 I_{2}}{r_{2}{ }^{2}-r_{1}{ }^{2}} \cdot \frac{x^{2}-r_{1}{ }^{2}}{x} \\
I_{2} M_{2,1} & =\int_{r_{1}}^{r_{2}} \frac{2 I_{2} x^{2}-r_{1}{ }^{2}}{r_{2}{ }^{2}-r_{1}{ }^{2}} d x \\
& =\frac{2 I_{2}}{r_{2}{ }^{2}-r_{1}{ }^{2}}\left(\frac{r_{2}{ }^{2}-r_{1}{ }^{2}}{2}-r_{1}{ }^{2} \log \frac{r_{2}}{r_{1}}\right) \\
& =I_{2}\left(\mathrm{I}-\frac{2 r_{1}{ }^{2}}{r_{2}{ }^{2}-r_{1}{ }^{2}} \log \frac{r_{2}}{r_{1}}\right) \\
M_{2,1} & =\mathrm{I}-\frac{2 r_{1}{ }^{2}}{r_{2}{ }^{2}-r_{1}{ }^{2}} \log \frac{r_{2}}{r_{1}}
\end{aligned}
$$

(d) $H_{2}=\frac{2 I_{2}}{r_{2}{ }^{2}-r_{1}{ }^{2}} \cdot \frac{x^{2}-r_{1}^{2}}{x}$ Weighting the flux in proportion to the area of the shell cut

$$
\begin{aligned}
I_{2} L_{2} & =\int r_{1}^{r_{2}}\left(\frac{2 I_{2}}{r_{2}{ }^{2}-r_{1}{ }^{2}} \cdot \frac{x^{2}-r_{1}{ }^{2}}{x}\right) \cdot \frac{x^{2}-r_{1}{ }^{2}}{r_{2}{ }^{2}-r_{1}{ }^{2}} d x \\
& =\frac{2 I_{2}}{\left(r_{2}{ }^{2}-r_{1}{ }^{2}\right)^{2}} \iint_{1} r^{2}\left(x^{3}-2 x r_{1}{ }^{2}+\frac{r_{1}^{4}}{x}\right) d x \\
& =I_{2}\left[\frac{\mathrm{I}}{2}-\frac{r_{1}{ }^{2}}{r_{2}{ }^{2}-r_{1}{ }^{2}}\left(\mathrm{I}-\frac{2 r_{1}{ }^{2}}{r_{2}{ }^{2}-r_{1}{ }^{2}} \log \frac{r_{2}}{r_{1}}\right)\right] \\
L_{2} & =\frac{I}{2}-\frac{r_{1}{ }^{2}}{r_{2}{ }^{2}-r_{1}{ }^{2}}\left(\mathrm{I}-\frac{2 r_{1}{ }^{2}}{r_{2}{ }^{2}-r_{1}{ }^{2}} \log \frac{r_{2}}{r_{1}}\right)
\end{aligned}
$$

(e) $\quad H_{1}=\frac{2 I_{1}}{x}$ Weighting according to area of shell cut.

$$
\begin{aligned}
I_{1} M_{1,2} & =\int_{r_{1}}^{r_{2}}\left(\frac{2 I_{1}}{x}\right) \frac{x^{2}-r_{1}{ }^{2}}{r_{2}{ }^{2}-r_{1}{ }^{2}} d x=I_{1}\left(\mathrm{I}-\frac{2 r_{1}{ }^{2}}{r_{2}{ }^{2}-r_{1}{ }^{2}} \log \frac{r_{2}}{r_{1}}\right) \\
M_{1,2} & =M_{2,1}=\mathrm{I}-\frac{2 r_{1}{ }^{2}}{r_{2}{ }^{2}-r_{1}{ }^{2}} \log \frac{r_{2}}{r_{1}}=M
\end{aligned}
$$


The above expressions may also be obtained from the expression given by Fowle ${ }^{16}$ for the internal inductance of a bimetallic wire for direct current. To do this, we will treat the core and shell as two circuits in parallel, each of which contains self-inductance and which act upon each other mutually. The equivalent induct. ance of two such circuits in parallel is given for zero frequency by

$$
L_{\mathrm{p}=0}=\frac{\left(L_{1} I_{1}+L_{2} I_{2}\right)\left(I_{1}+I_{2}\right)-I_{1} I_{2}\left(L_{1}+L_{2}-2 M\right)}{\left(I_{1}+I_{2}\right)^{2}}
$$

The expression for the self-inductance when the shell is of unit permeability and the core of permeability $\mu$ becomes

$$
L_{\mathrm{p}=0}=\frac{\frac{\mu}{2} I_{1}{ }^{2}+2 I_{1} I_{2}+\frac{\mathrm{I}}{2} I_{2}{ }^{2}\left(\mathrm{I}-\frac{2 r_{1}{ }^{2}}{r_{2}{ }^{2}-r_{1}{ }^{2}}\right)+2\left(I_{1}-I_{2} \frac{r_{1}{ }^{2}}{r_{2}{ }^{2}-r_{1}{ }^{2}}\right)^{2} \log \frac{r^{2}}{r_{1}}}{\left(I_{1}+I_{2}\right)^{2}}
$$

where $I_{1}$ is the core current and $I_{2}$ the shell current.

If we equate the two expressions for $L_{p=o}$ and also equate the coefficients of $I_{1}{ }^{2}, I_{1} I_{2}$, and $I_{2}{ }^{2}$, we get

$$
\begin{aligned}
& L_{1}=\frac{\mu}{2}+2 \log \frac{r_{2}}{r_{1}} \\
& M=\mathrm{I}-2 \frac{r_{1}{ }^{2}}{r_{2}^{2}-r_{1}^{2}} \log \frac{r_{2}}{r_{1}} \\
& L_{2}=\frac{\mathrm{I}}{2}-\left(\frac{r_{1}{ }^{2}}{r_{2}{ }^{2}-r_{1}{ }^{2}}\right)\left[\mathrm{I}-\frac{2 r_{1}{ }^{2}}{r_{2}{ }^{2}-r_{1}{ }^{2}} \log \frac{r_{2}}{r_{1}}\right]
\end{aligned}
$$

which are identical with the expressions obtained above.

We can now extend the treatment of the bimetallic wire as two circuits in parallel to the case of the frequency greater than zero and compute the effective resistance and inductance of the conductor for a given frequency. If we consider the distribution of the current in the shell to remain uniform, it is then necessary to take into account only the effects of change of distribution in the core. Since a change of distribution in the core will for the same core current affect only the field inside the core itself, only $L_{1}^{\prime}=\frac{\mu}{2}$ of the above inductances will be altered. We can, however, com- 
pute the value of $L^{\prime}{ }_{1}$ for a given frequency from the formula already given for a straight cylindrical wire of constant permeability.

The resistance of the core will also be altered by the change of distribution, but the effective resistance for a given frequency can also be computed by the formula previously given.

We obtain then from the expressions for the equivalent resistance and inductance of the divided circuit at a frequency $f=\frac{p}{2 \pi}$ the following formulas for the effective resistance and inductance of a bimetallic wire:

(8)

$R^{\prime}=\frac{\left[R_{1} R_{2}-p^{2}\left(L_{1} L_{2}-M^{2}\right)\right]\left(R_{1}+R_{2}\right)+p^{2}\left(R_{1} L_{2}+R_{2} L_{1}\right)\left(L_{1}+L_{2}-2 M\right)}{\left(R_{1}+R_{2}\right)^{2}+p^{2}\left(L_{1}+L_{2}-2 M\right)^{2}}$ and

(9)

$$
L^{\prime}=\frac{\left(R_{1} L_{2}+R_{2} L_{1}\right)\left(R_{1}+R_{2}\right)-\left[R_{1} R_{2}-p^{2}\left(L_{1} L_{2}-M^{2}\right)\right]\left(L_{1}+L_{2}-2 M\right)}{\left(R_{1}+R_{2}\right)^{2}+p^{2}\left(L_{1}+L_{2}-2 M\right)^{2}}
$$

Where $R_{1}$ is the computed effective resistance of the core and $R_{2}$ is the (assumed) constant or direct current resistance of the shell and $L_{1}=L^{\prime}{ }_{1}$ (computed) $+L^{\prime \prime}{ }_{1}$.

The formulas were checked and estimates of the errors due to the assumption of uniform distribution in the shell were obtained by computing the effective resistance and inductance of a solid hard-drawn copper conductor. The core and shell were given the same dimensions as those used later in the computation of a No. 4 bimetallic wire. In effect the computation gave the effective resistance and inductance of a larger wire from the effective resistance and inductance of a wire of smaller radius. The values could then be directly calculated for the large wire by the exact formulas and the two sets compared. The following values were used in the computation: $r_{1}=0.2607 \mathrm{~cm}, r_{2}=0.223 \mathrm{I} \mathrm{cm}, \sigma=1770.6$ abs. units.

$R_{2}=3.0983$ ohms per kilometer.

$L^{\prime \prime}{ }_{1}=3$ I.I 4 microhenrys per kilometer.

$L_{2}=9.56$ microhenrys per kilometer.

$M=\mathrm{I} 4.78$ microhenrys per kilometer. 


\section{Effective Resistance and Inductances of Core}

\begin{tabular}{|c|c|c|}
\hline $\begin{array}{c}\text { Frequency } \\
\text { (cycles per } \\
\text { second) }\end{array}$ & $\begin{array}{c}\mathbf{R}_{1} \text { (ohms per } \\
\text { kilometer) }\end{array}$ & $\begin{array}{c}\mathbf{L}_{1} \text { (micro- } \\
\text { henrys per } \\
\text { kllometer) }\end{array}$ \\
\hline 0 & 1.1323 & 50.00 \\
1000 & 1.1608 & 49.37 \\
3000 & 1.3538 & 45.19 \\
5000 & 1.6205 & 39.64 \\
\hline
\end{tabular}

The following values were obtained for the effective resistance and inductance of the larger wire by the formulas (5) and (6) and the exact formulas (3) and (4), respectively:

\begin{tabular}{|c|c|c|c|c|}
\hline Cycles per second............... & 0 & 1000 & 3000 & 5000 \\
\hline- & \multicolumn{4}{|c|}{ Effective resistance (ohms per kilometer) } \\
\hline Approximate formula.................. & 0.8293 & 0.8667 & 1.0912 & 1.3432 \\
\hline Exact formula ........................... & 0.8293 & 0.8676 & 1.0972 & 1.3582 \\
\hline \multirow[t]{2}{*}{ Per cent difference... } & 0.0 & 0.1 & 0.6 & 1.1 \\
\hline & \multicolumn{4}{|c|}{$\begin{array}{l}\text { Effective inductance (microhenrys } \\
\text { per kilometer) }\end{array}$} \\
\hline Approximate formula .............. & 50.00 & 48.86 & 42.20 & 35.30 \\
\hline 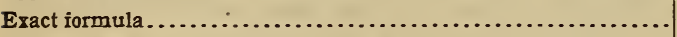 & 50.00 & 48.85 & 42.14 & 35.14 \\
\hline Per cent difference............ & 0.0 & 0.0 & 0.1 & 0.5 \\
\hline
\end{tabular}

The error even at 5000 cycles per second is only I.I per cent for the resistance and 0.5 per cent for the inductance and in the direction to be explained by neglecting the changes in distribution of the current in the shell. The values given by the approximate formulas approach, as limiting values for increasing frequency, the resistance and inductance of the shell, while actually the resistance should become infinite and the (internal) inductance zero. For a given frequency the values for the bimetallic wire with a steel core would be more strongly determined by those for the shell than in the above case, and hence somewhat higher errors may be expected. A number of comparisons will be made later, between the values for actual wires as determined by experiment and those given by the formulas (8) and (9). 


\section{EXPERIMENTAL. METHODS}

\section{THE BRIDGE}

The Anderson bridge, used in the measurement of inductance with direct current, was also used, with a few modifications, for the determinations of effective resistance and inductance. $P, R$, $S, r$, and $C$ (Fig. I2) were the same, but the $Q$ arm contained in addition to the wire under measurement (or the substitute link) the manganin or copper links and the mercury slider, a low resistance variable inductance of about 50 microhenrys range. The indicating instrument was a vibration galvanometer of the Rubens type for frequencies of 50 or 100 cycles per second or a low resistance telephone for the higher frequencies. The current for the bridge was supplied by two generators, one for 50 and roo cycles and the other for frequencies from 500 to 3000 cycles. These machines were run by storage batteries. A I 2 to I or 24 to I step-down transformer of 600 watts capacity was used to reduce the voltage on the bridge and to
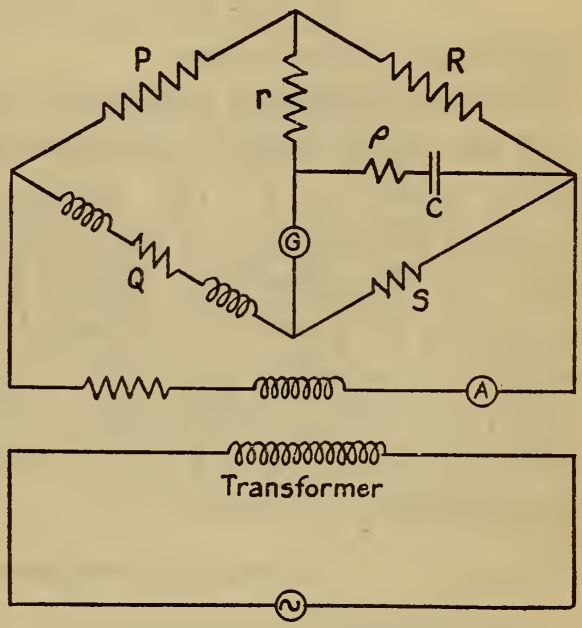

FIG. 12.-Anderson bridge increase the available current. The current in the bridge was read by Hartmann and Braun hot-wire ammeters of $\mathrm{I}, 5$, and Io amperes range. A variable resistance $\rho$ was introduced into the bridge in series with the condenser $C$ for the following purpose: The balance of an ideal Anderson bridge-that is, a bridge made up of completely noninductive resistances, perfect condenser, etc.--is independent of the frequency and the equations for balance when $P=R$, are

$$
\begin{aligned}
& L=C S(R+2 r) \\
& S-Q=o
\end{aligned}
$$

In an actual bridge, however, the resistance coils have residual inductance and the condenser is absorbing. On this account, the 
bridge balance at high frequencies and especially the resistance balance, will change considerably with the frequency. In a bridge such as that used in this work where the range of balance is somewhat limited, even though no error may be introduced, considerable changes in balance with the frequency are inconvenient.

If we assume the residual inductance $1_{3}$ in $P$ and in $R, 1_{4}$ in $S$ and $1_{5}$ in $r$ and a resistance $\rho$ in series with a perfect condenser $C$, the equation ${ }^{17}$ which gives the condition for a resistance balance may be brought into the form

$$
S-Q=p^{2} C\left[(R+2 r) 1_{4}+S 1_{3}+2 S 1_{5}-L \rho\right]
$$

neglecting smaller terms.

In a low-resistance bridge the residual inductances are positive and the factor within the brackets can be reduced to zero by a proper choice of $\rho$. The resistance balance of the bridge then becomes independent of the frequency. However, the condenser may not be perfect and though it then is equivalent at a given frequency to a perfect condenser with a resistance in series, this resistance depends upon the frequency and an exact compensation for all frequencies is not possible. However, with a good mica condenser, as was used in this work, the changes in balance can be made very small.

\section{RANGE OF THE MEASUREMENTS}

The effective resistance and inductance of condictors which contain iron, depend in general both upon the frequency and the current strength. Also as in the case of the direct-current measurements, it was found that for solid iron wires consistent results could only be obtained when the iron was demagnetized. The procedure was to demagnetize the wire, using a low-frequency current by reducing the current slowly to one or two tenths of an ampere, from a considerably higher value than the maximum used in the experimental determinations. Then, at a given frequency, the measurements were made with successively increasing currents and the wire was again demagnetized before taking up another frequency. The range of current strengths was from 0.5

17 The derivation is similar to that given by Rosa and Grover, this Bulletin, 1, p. 304; $1904-5$ (Scientifie Paper No. 14). 
to Io amperes and frequencies of $50,100,500$, 1000, and 3000 cycles per second were used in addition to the direct current measurements.

A high accuracy in the measurements was considered unnecessary on account of the considerable variations that could be expected between different samples of the same grade of material. For this reason no attempt was made to control the temperature of the wire under investigation; the measurements were made at room temperatures which for most of the work varied from about $20^{\circ}$ to $23^{\circ} \mathrm{C}$.

\section{METHOD USED FOR 50 AND 100 CYCLES}

The measurements at 50 and roo cycles were made in a manner similar to that used in the direct-current measurements, excepting that here the resistance as well as the inductance was considered. The resistance changes were measured by reading the settings of the calibrated mercury slider when the range of this was sufficient, otherwise the balance was brought within range of the mercury slider by substituting manganin links for similar copper links, the resistance changes due to the substitution having been determined by separate experiments. The inductance changes were determined from the settings of the resistance $r$. The frequency of the current was adjusted by means of the two vibration galvanometers used at these frequencies to determine the balance of the bridge. One was tuned to 50 and the other to roo cycles and the frequency of the current was always adjusted to obtain the maximum sensibility. This determined the frequency to well within a per cent.

The method of measurement was to balance the bridge with a substitute link in place of the wire under measurement and with, say, 3 amperes current at 50 cycles in the bridge. The iron wire was then introduced and another balance obtained. Finally the bridge was balanced on direct current of the same strength. The difference in the setting of the resistance $r$ between the first two balances gives the inductance at 50 cycles and 3 amperes when corrected for the inductance of the substitute link. The difference in the resistances of the mercury slider and manganin or copper links between the last two balances gives the change in resistance of the wire from direct current to 50 cycles and 3 amperes. 


\section{METHOD USED FOR 500, 1000, AND 3000 CYCLES}

At the higher frequencies the above method would be liable to considerable error and the following procedure was used:

(I) The bridge containing the wire under measurement was balanced at roo cycles and desired current. Readings of $r$ and mercury slider were recorded.

(2) The bridge was balanced at the higher frequency by means of $r$ and the mercury slider and if necessary by substituting a copper for a manganin link and these were recorded.

(3) The substitute link was introduced into the bridge and another balance at the higher frequency obtained. This time the inductance balance was obtained by means of the variable selfinductance, $r$ remaining unchanged. The mercury slider was read.

(4) A final balance at Ioo cycles with the substitute link was obtained by means of $r$ and slider.

By this procedure a resistance and inductance which do not change appreciably with the frequency are substituted for the resistance and inductance of the iron wire at the higher frequency, the other parts of the bridge remaining unchanged. Then the determinations at roo cycles serve to compare the values for high and low frequency or to measure the changes from roo cycles to the higher frequency.

The resistance change is given by the difference in the readings of the mercury slider in going from (I) to (2) and then again from (3) to (4). Any changes in resistance links in the first interval must also be considered. In the latter interval the mercury slider alone will suffice on account of the resistance $\rho$ in series with the condenser.

The inductance change is given by the difference in the settings of $r$ in ( $\mathrm{I}$ ) and (4). No calibration of the variable inductance is necessary.

The method has the advantage of measuring the changes due to frequency in the wire under investigation and eliminates changes due to frequency in all parts of the bridge excepting the substitutes for the wire. The latter consisted of a variation of the mutual inductance between the two coils of a so-called variable self- 
inductance, and a variation of resistance by means of the mercury slider, the resistance links of manganin wire and the substitute link. The self-inductance was wound with stranded wire, each strand insulated, and would probably have introduced no error even if wound with solid wire, for we are here interested in the mutual inductance between the two coils which, in general, is not strongly influenced by frequency. The mercury slider and manganin links would not show appreciable skin effect at 3000 cycles due to high resistivity and small cross section. In the measurements upon solid iron wire where straight pieces of about I.4 meters were included in the bridge, the substitute link was a copper wire which was made fairly heavy for convenience in handling. This had an appreciable skin effect at I000 and 3000 cycles and the small corrections for this were calculated and applied. In the case of the solid copper and copper-steel bimetallic wires of which considerable lengths were used and strung in a rectangular shape, the ends were close together and a short substitute link of manganin was used for which no correction was necessary.

It was found that errors could be introduced into the measurement by a drift in the resistance balance of the bridge between (I) and (2), and (3) and (4). This error was reduced to a negligible amount by putting the measuring current on the bridge for a sufficient time before taking a measurement and by the procedure in which the wire under measurement was first included in the bridge and then the low temperature coefficient substitutes.

Errors could be introduced also by mutual inductance effects between different parts of the bridge and upon the indicating instrument, which changed when the substitution was made. These were guarded against in the arrangement of the bridge and investigated experimentally.

\section{A TEST MEASUREMENT}

Probably the most conclusive evidence of the freedom of the method from errors is shown by the test of the accuracy in measuring the small changes in a No. Io solid copper wire. These could also be computed and compared with the measured values. 
A length of about $32.5 \mathrm{~m}$ of the above wire was strung in a rectangular shape with about $30 \mathrm{~cm}$ spacing between the wires. The total resistance was $0.108 \mathrm{ohm}$ and the inductance as strung 37.0 microhenrys. The changes in resistance and inductance as measured and computed for 100 to 2000 and 100 to 3000 cycles were as follows:

\begin{tabular}{|c|c|c|c|}
\hline Cycles & Data & $\begin{array}{l}\text { Change in } \\
\text { resistance } \\
\text { (ohms) }\end{array}$ & $\begin{array}{c}\text { Change in } \\
\text { inductance } \\
\text { (centi- } \\
\text { meters) }\end{array}$ \\
\hline \multirow{3}{*}{100 to $2000 .}$. & Experimental. & +0.00116 & -13 \\
\hline & $\{$ Computed.... & +0.00132 & -11 \\
\hline & Experimental. & +0.00304 & -26 \\
\hline 100 to $3000 .$. & Computed.... & +0.00300 & -25 \\
\hline
\end{tabular}

The measurements were made with 3 amperes bridge current; the values for 2000 cycles are the mean of seven determinations, those for 3000 cycles the mean of nine. The agreement is in general better than would be expected from the sensitivity of the bridge under the conditions of measurement. Small corrections (about $2 \mathrm{~cm}$ ) were made for changes in inductance with the setting of the mercury slider; in later work this correction was of no consequence.

\section{THE EFFECTIVE RESISTANCE AND INDUCTANCE OF IRON WIRES}

\section{EXPERIMENTAL RESULTS}

Measurements of the effective resistance and inductance of iron wires were carried out upon the samples of telegraph and telephone wires previously mentioned. Three wires each of the grades E. B. B. (Extra Best Best) and Steel were used and Table I gives data with respect to them. The resistance measurements were made at about $20^{\circ} \mathrm{C}$ 

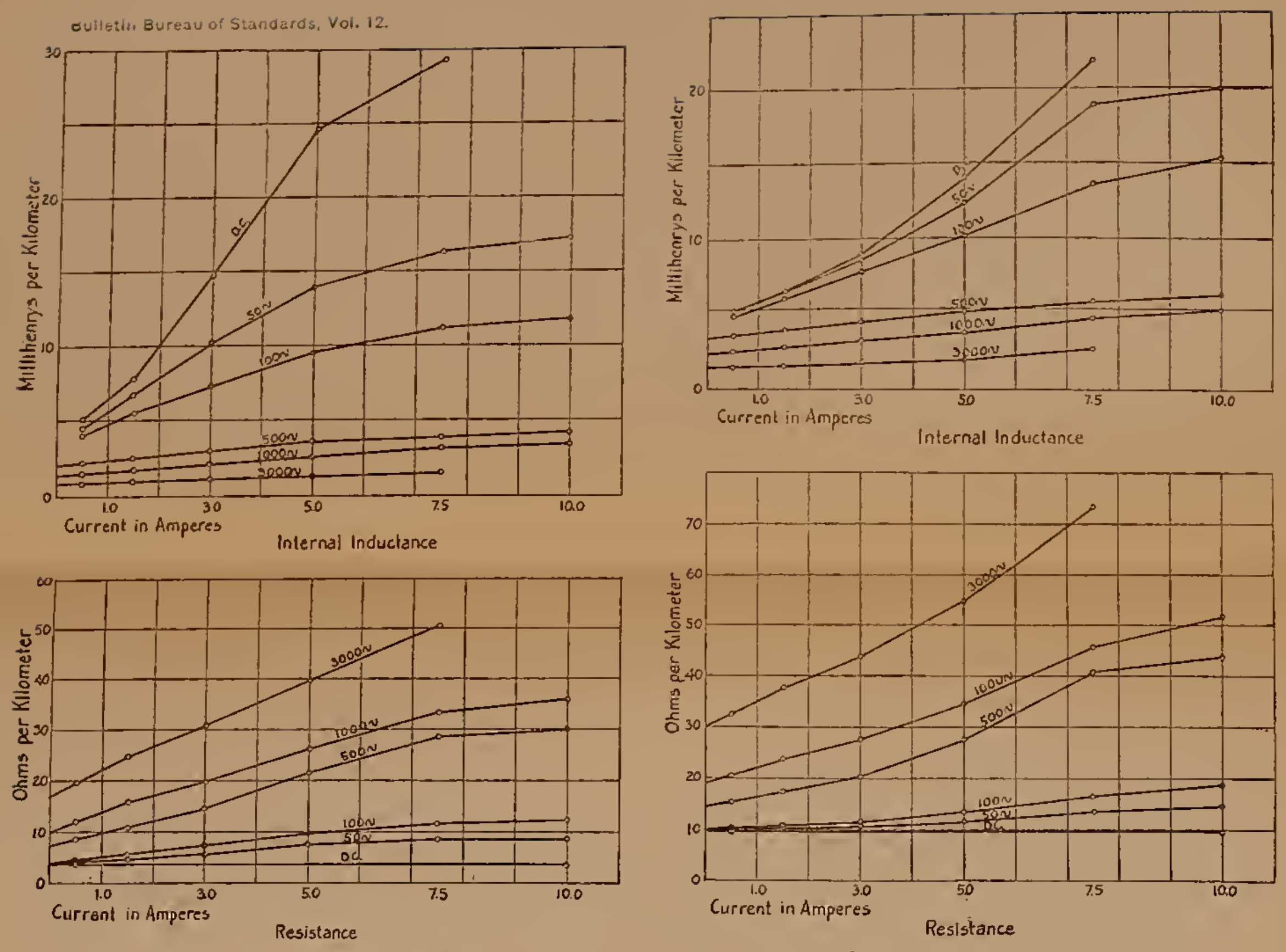

Fig. 13. - No. 4 E. B. B. wire

Fig. I6.-No. 8. Stecl wire
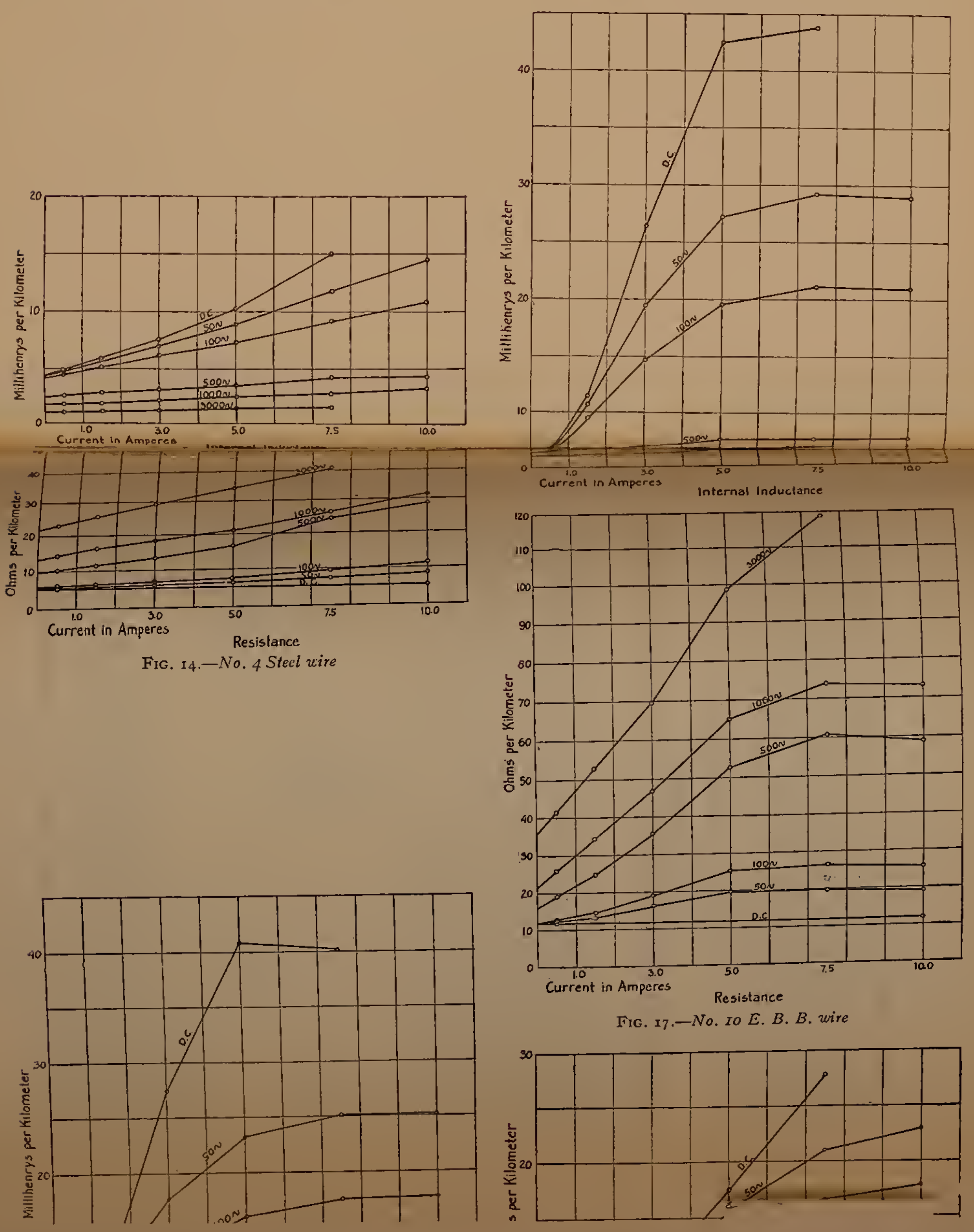

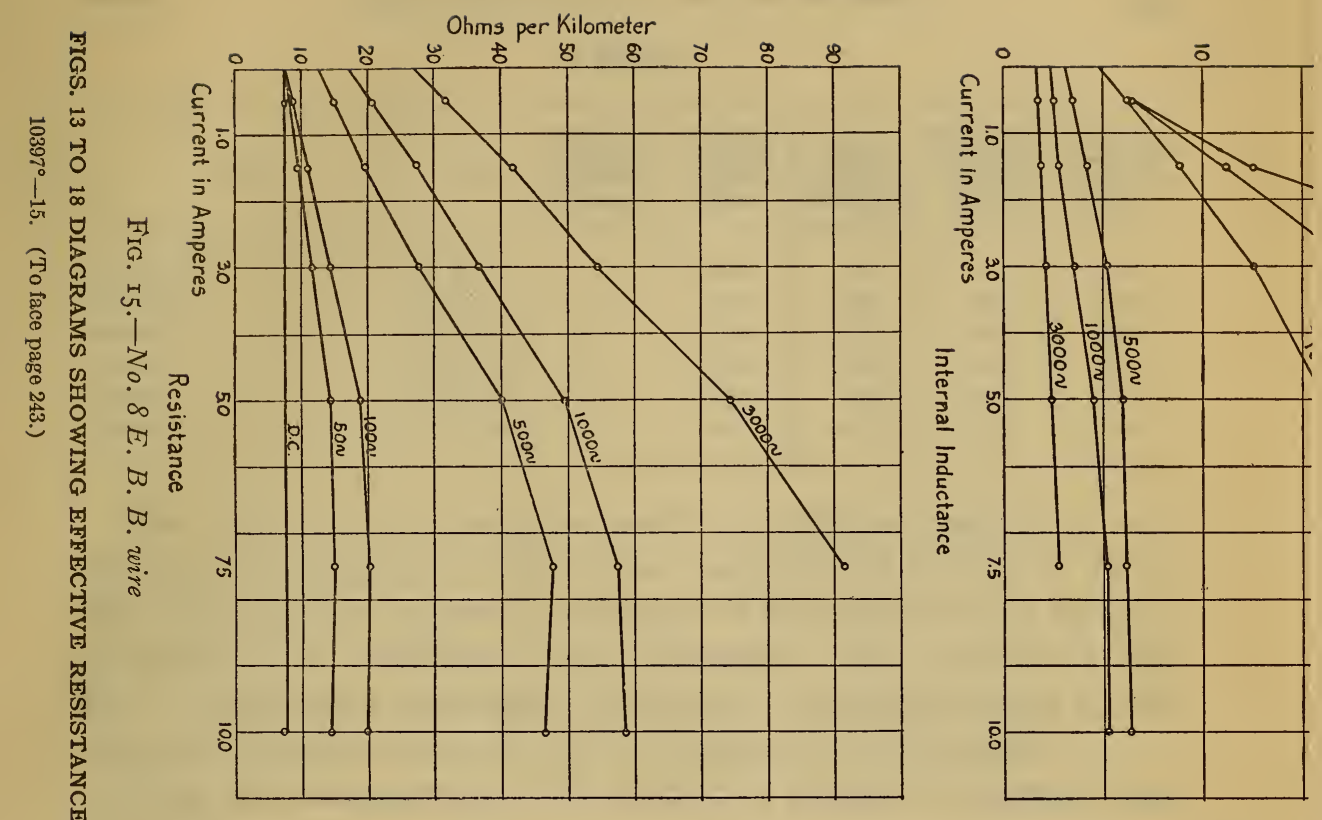

(3)
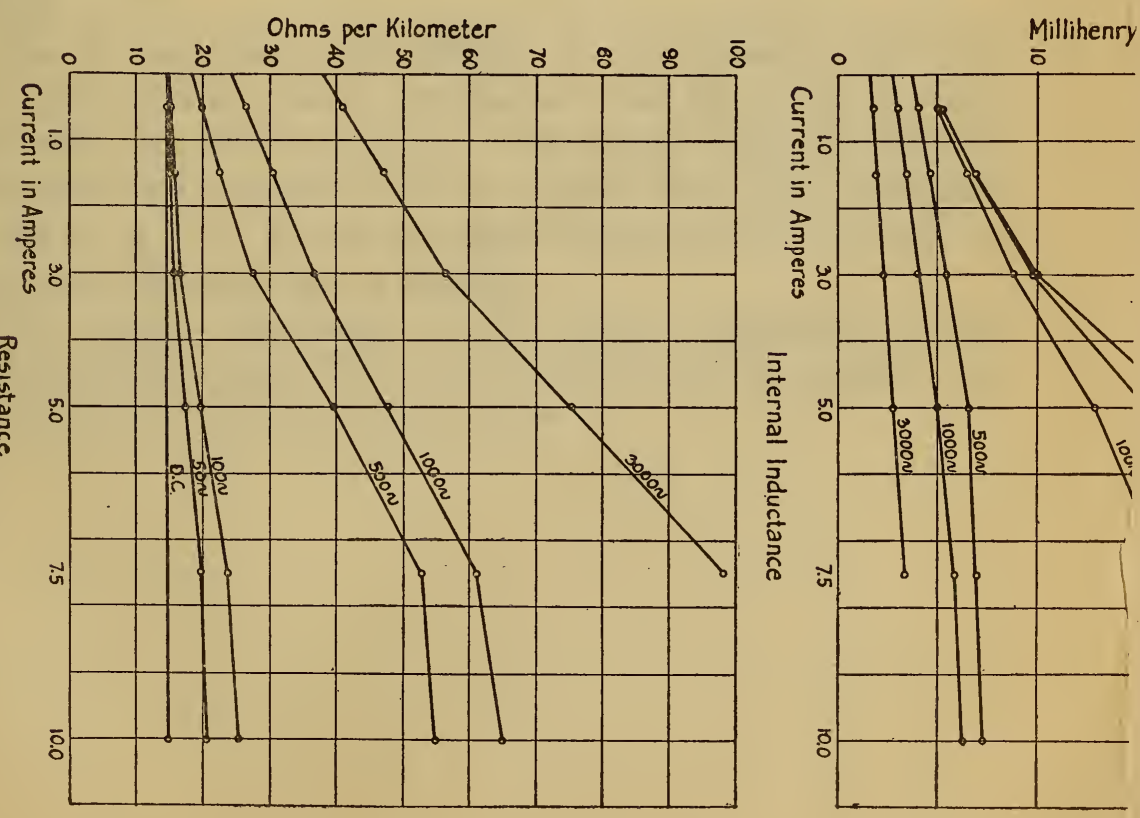
TABLE 1

\begin{tabular}{|c|c|c|c|c|c|c|}
\hline Wire & Gage & $\begin{array}{l}\text { Nominal } \\
\text { diameter } \\
\text { (milli- } \\
\text { meters) }\end{array}$ & $\begin{array}{c}\text { Measured } \\
\text { diameter } \\
\text { (milli- } \\
\text { meters) }\end{array}$ & $\begin{array}{l}\text { D. C. } \\
\text { resistance } \\
\text { (ohms per } \\
\text { kilometer) }\end{array}$ & $\begin{array}{c}\text { Resistivity } \\
\text { (microhm- } \\
\text { centi- } \\
\text { meters) }\end{array}$ & $\begin{array}{c}\text { Per cent } \\
\text { conductiv- } \\
\text { ity of H. D. } \\
\text { copper }\end{array}$ \\
\hline 4 E. B. B.. & B. W. G.. & 6.0 & 6.04 & 3.74 & 11.7 & 15.1 \\
\hline 8 E.B.B.. & B. W. G.. & 4.2 & 4.18 & 7.70 & 10.6 & 16.8 \\
\hline 10 E. В. В.. & B. W. G.. & 3.4 & 3.39 & 11.9 & 10.8 & 16.5 \\
\hline 4 Steel..... & St. w. G.. & 5.7 & 5.68 & 5.34 & 13.5 & 13.1 \\
\hline 8 Steel... & B. W. G.. & 4.2 & 4.16 & 9.69 & 13.2 & 13.4 \\
\hline 10 Steel..... & B. W. G.. & 3.40 & 3.41 & 14.7 & 13.4 & 13.2 \\
\hline
\end{tabular}

The results of the measurements of effective resistance and inductance are given in Tables 2 to 7 and plotted in Figs. I 3 to 18. The resistances are given in ohms per kilometer and the internal inductances in millihenrys per kilometer. The values for the D. C. inductances correspond to currents which are equal to the maximum values of the R. M. S. currents in the headings.

From the measurements the following points of interest may be noted:

I. Due to the lower permeability of the material, the Steel wires rapidly become better conductors than the $\mathrm{E}$. B. B. wires of the same size as the frequency and current strength increase. At 50 cycles and 5 amperes the No. 4 Steel has a lower resistance than the No. 4 E. B. B. and the same is true of the Nos. 8 and ro at the same frequency and 3 amperes.

2. The internal inductance at the higher frequencies is but slightly dependent upon the current strength and is, roughly, the same in value for all of the conductors. 


\section{TABLE 2}

No. 4 E. B. B.

\begin{tabular}{|c|c|c|c|c|c|c|}
\hline 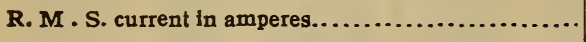 & 0.5 & .1 .5 & 3.0 & 5.0 & 7.5 & 10.0 \\
\hline & \multicolumn{6}{|c|}{ Resistance (ohms per kilometer) } \\
\hline \multicolumn{7}{|l|}{ Frequency: } \\
\hline D. C... & 3.74 & 3.74 & 3.74 & 3.74 & 3.74 & 3.74 \\
\hline 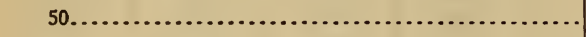 & 4.04 & 4.58 & 5.77 & 7.62 & 8.64 & 8.80 \\
\hline $100 \ldots \ldots \ldots \ldots \ldots$ & 4.53 & 5.61 & 7.27 & 9.99 & 11.9 & 12.4 \\
\hline $500 \ldots \ldots \ldots \ldots \ldots \ldots$ & 8.53 & 10.9 & 14.7 & 21.5 & 28.7 & 30.0 \\
\hline 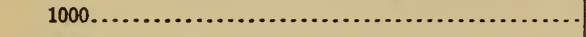 & 11.9 & 15.7 & 19.9 & 26.1 & 33.3 & 35.9 \\
\hline \multirow[t]{2}{*}{ 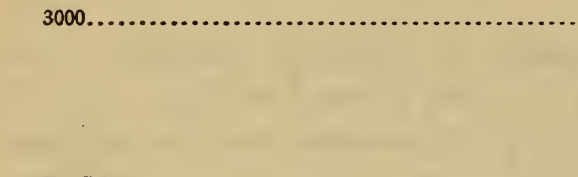 } & 19.5 & 24.7 & 30.9 & 39.9 & 50.5 & ........ \\
\hline & \multicolumn{6}{|c|}{$\begin{array}{l}\text { Internal inductance (millihenrys per } \\
\text { kilometer) }\end{array}$} \\
\hline D. C. ${ }^{18} \ldots \ldots \ldots \ldots$ & 5.1 & 7.8 & 14.7 & 24.6 & 29.3 & $\ldots \ldots \ldots \ldots$ \\
\hline $50 \ldots \ldots \ldots \ldots \ldots \ldots \ldots \ldots \ldots \ldots \ldots \ldots \ldots \ldots \ldots \ldots \ldots \ldots \ldots$ & 4.5 & 6.7 & 10.1 & 13.9 & 16.3 & 17.2 \\
\hline 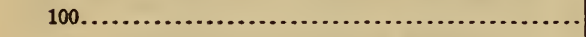 & 4.0 & 5.5 & 7.3 & 9.5 & 11.1 & 11.7 \\
\hline 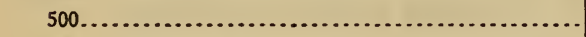 & 2.2 & 2.6 & 3.0 & 3.6 & 3.9 & 4.2 \\
\hline 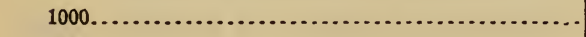 & 1.5 & 1.7 & 2.1 & 2.6 & 3.1 & 3.4 \\
\hline 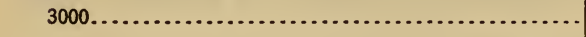 & 0.9 & 1.0 & 1.1 & 1.3 & 1.6 & ........ \\
\hline
\end{tabular}

TABLE 3

No. 4 Steel

\begin{tabular}{|c|c|c|c|c|c|c|}
\hline 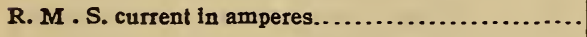 & 0.5 & 1.5 & 3.0 & 5.0 & 7.5 & 10.0 \\
\hline & \multicolumn{6}{|c|}{ Resistance (ohms per kilometer) } \\
\hline \multicolumn{7}{|l|}{ Frequency: } \\
\hline D. C.... & 5.34 & 5.34 & 5.34 & 5.34 & 5.34 & 5.34 \\
\hline $50 \ldots \ldots$. & 5.50 & 5.70 & 6.00 & 6.51 & 7.51 & 8.56 \\
\hline $100 \ldots \ldots$. & 6.01 & 6.39 & 6.98 & 7.92 & 9.53 & 11.4 \\
\hline $500 \ldots \ldots$. & 10.4 & 11.6 & 13.4 & 16.5 & 24.1 & 28.5 \\
\hline 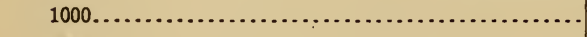 & 14.1 & 16.1 & 18. 3 & 21.0 & 26.1 & 31.4 \\
\hline \multirow[t]{2}{*}{ 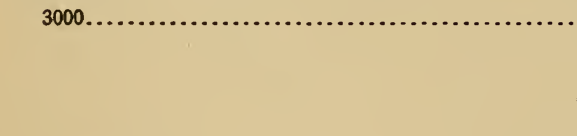 } & 23.0 & 25.5 & 29.3 & 34.1 & 41.1 & ....... \\
\hline & \multicolumn{6}{|c|}{$\begin{array}{l}\text { Internal inductance (millihenrys per } \\
\text { kilometer) }\end{array}$} \\
\hline D. C. 18 .. & 4.9 & 5.9 & 7.6 & 10.2 & 15.0 & \\
\hline $50 \ldots \ldots$ & 4.6 & 5.7 & 7.0 & 8.9 & 11.8 & 14.5 \\
\hline 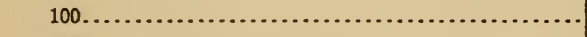 & 4.4 & 5.1 & 6.1 & 7.3 & 9.1 & 10.8 \\
\hline $500 \ldots .$. & 2.6 & 2.8 & 3.1 & 3.5 & 3.9 & 4.3 \\
\hline $100 n \ldots \ldots \ldots \ldots \ldots \ldots$ & 1.8 & 1.9 & 2.2 & 2.5 & 2.8 & 3.3 \\
\hline 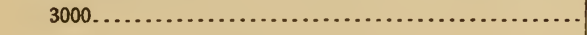 & 1.0 & 1.1 & 1.2 & 1.4 & 1.6 & ....... \\
\hline
\end{tabular}

${ }_{18}$ The values of inductance for D. C. correspond to the maximum values of the R.M. S. currents given in the headings. 
TABLE 4

No. 8 E. B. B

\begin{tabular}{|c|c|c|c|c|c|c|}
\hline 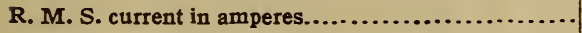 & 0.5 & 1.5 & 3.0 & 5.0 & 7.5 & 10.0 \\
\hline & \multicolumn{6}{|c|}{ Resistance (ohms per kilometer) } \\
\hline \multicolumn{7}{|l|}{ Frequency: } \\
\hline D. C $\ldots \ldots \ldots \ldots \ldots \ldots \ldots \ldots \ldots$ & 7.70 & 7.70 & 7.70 & 7.70 & 7.70 & 7.70 \\
\hline 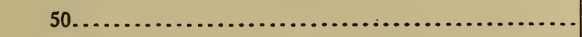 & 8.10 & 9.27 & 11.8 & 14.5 & 15.1 & 14.7 \\
\hline 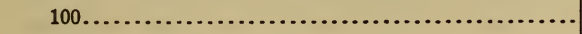 & 8.86 & 11.0 & 14.4 & 19.0 & 20.5 & 20.1 \\
\hline 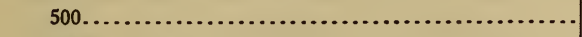 & 15.0 & 19.8 & 27.6 & 40.1 & 47.9 & 46.8 \\
\hline 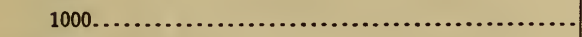 & 20.7 & 27.5 & 36.8 & 49.8 & 57.5 & 58.6 \\
\hline \multirow[t]{2}{*}{ 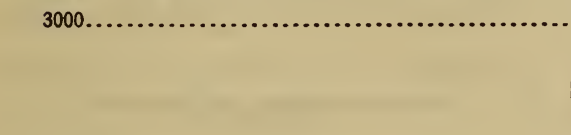 } & 32.0 & 41.9 & 54.5 & 74.5 & 91.5 & (........ \\
\hline & \multicolumn{6}{|c|}{$\begin{array}{c}\text { Internal inductance (millihenrys per } \\
\text { kilometer) }\end{array}$} \\
\hline 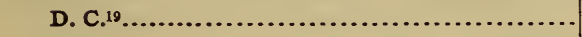 & 6.6 & 12.5 & 27.4 & 40.8 & 40.2 & $\ldots \ldots$ \\
\hline 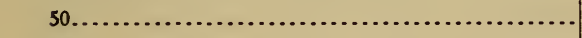 & 6.5 & 11.1 & 17.7 & 23.2 & 25.1 & 25.2 \\
\hline 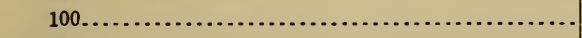 & 5.9 & 8.9 & 12.6 & 16.1 & 17.6 & 17.7 \\
\hline 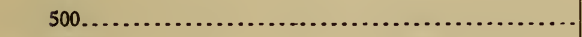 & 3.5 & 4.2 & 5.2 & 6.0 & 6.2 & 6.4 \\
\hline $1000 \ldots \ldots \ldots \ldots \ldots \ldots \ldots \ldots$ & 2.5 & 2.8 & 3.6 & 4.6 & 5.2 & 5.3 \\
\hline $3000 \ldots \ldots \ldots \ldots \ldots . . . . . . . .$. & 1.7 & 1.9 & 2.1 & 2.4 & 2.8 & (........ \\
\hline
\end{tabular}

TABLE 5

No. 8 Steel

\begin{tabular}{|c|c|c|c|c|c|c|}
\hline 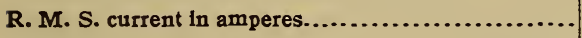 & 0.5 & 1.5 & 3.0 & 5.0 & 7.5 & 10.0 \\
\hline & \multicolumn{6}{|c|}{ Resistance (ohms per kilometer) } \\
\hline \multicolumn{7}{|l|}{ Frequency: } \\
\hline 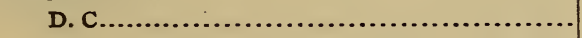 & 9.69 & 9.69 & 9.69 & 9.69 & 9.69 & 9.69 \\
\hline 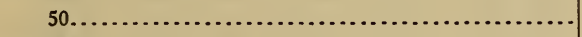 & 9.80 & 10.1 & 10.5 & 11.6 & 13.3 & 14.5 \\
\hline 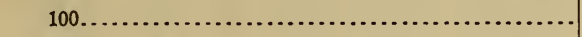 & 10.2 & 10.7 & 11.5 & 13.3 & 16.4 & 18.5 \\
\hline 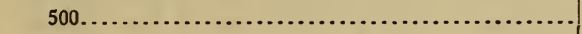 & 15.3 & 17.2 & 20.2 & 27.7 & 40.7 & 43.8 \\
\hline 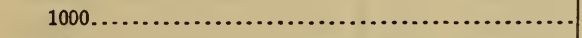 & 20.5 & 23.6 & 27.5 & 34.3 & 45.7 & 51.4 \\
\hline \multirow[t]{2}{*}{ 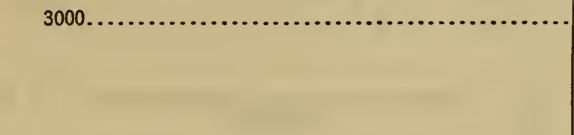 } & 32.5 & 37.5 & 43.7 & 54.7 & 73.1 & ......... \\
\hline & \multicolumn{6}{|c|}{$\begin{array}{l}\text { Internal inductance (millihenrys per } \\
\text { kilometer) }\end{array}$} \\
\hline 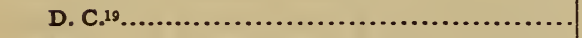 & 5.2 & 6.6 & 9.0 & 14.0 & 21.8 & $\ldots \ldots \ldots$ \\
\hline $50 \ldots \ldots \ldots \ldots \ldots \ldots \ldots \ldots \ldots$ & 5.15 & 6.5 & 8.6 & 12.3 & 17.2 & 19.9 \\
\hline 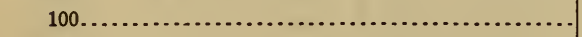 & 4.9 & 6.0 & 7.7 & 10.1 & 13.6 & 15.3 \\
\hline 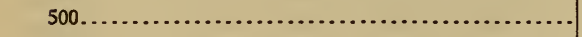 & 3.6 & 3.9 & 4.4 & 5.1 & 5.8 & 6.3 \\
\hline 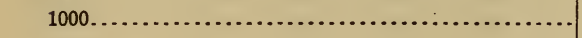 & 2.5 & 2.8 & 3.2 & 3.7 & 4.7 & 5.3 \\
\hline 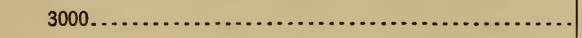 & 1.5 & 1.6 & 1.8 & 2.0 & 2.7 & $\ldots \ldots$ \\
\hline
\end{tabular}

19 The values of inductance for D. C. correspond to the maximum values of the R. M. S. currents given in the headings. 


\section{TABLE 6}

No. 10 E. B. B

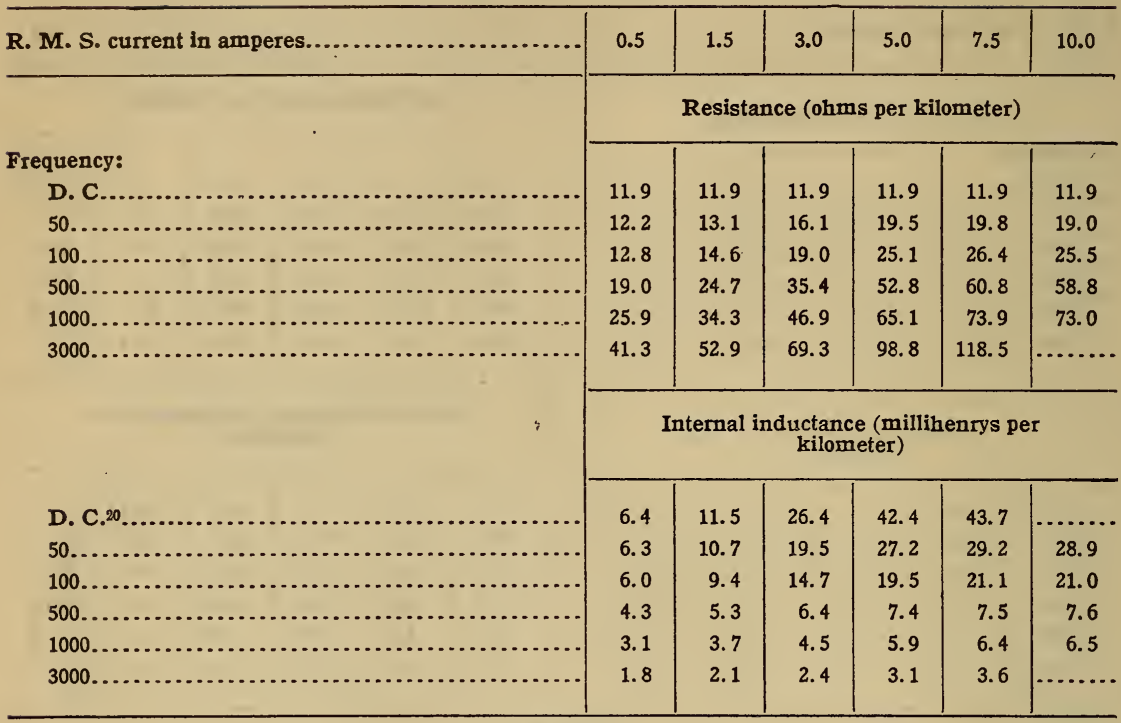

TABLE 7

No. 10 Steel

\begin{tabular}{|c|c|c|c|c|c|c|}
\hline 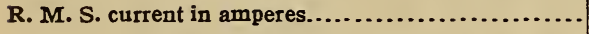 & 0.5 & 1.5 & 3.0 & 5.0 & 7.5 & 10.0 \\
\hline & \multicolumn{6}{|c|}{ Resistance (ohms per kilometer) } \\
\hline Frequency: & & & & & - & \\
\hline 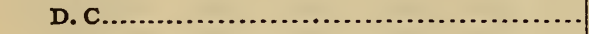 & 14.7 & 14.7 & 14.7 & 14.7 & 14.7 & 14.7 \\
\hline 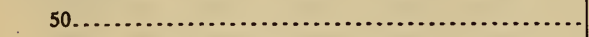 & 14.8 & 15.1 & 15.7 & 17.4 & 19.7 & 20.2 \\
\hline 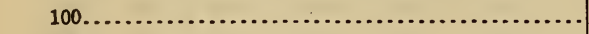 & 15.1 & 15.7 & 16.8 & 19.9 & 23.6 & 25.2 \\
\hline 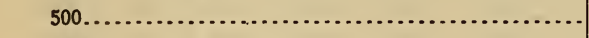 & 19.9 . & 22.7 & 27.5 & 39.7 & 52.8 & 54.6 \\
\hline 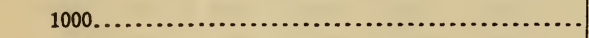 & 26.3 & 30.7 & 36.7 & 47.8 & 61.0 & 64.9 \\
\hline \multirow[t]{3}{*}{ 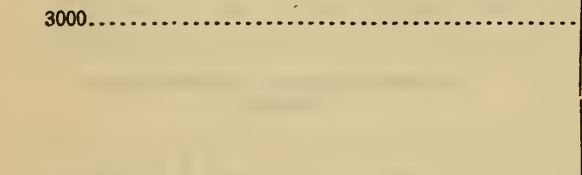 } & 40.7 & 47.2 & 56.4 & 75.1 & 98.1 & ( - n....... \\
\hline & \multicolumn{6}{|c|}{$\begin{array}{l}\text { Internal inductance (millihenrys per } \\
\text { kilometer) }\end{array}$} \\
\hline & 5.2 & 6.8 & 10.0 & 17.4 & 27.8 & \\
\hline 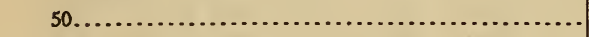 & 5.2 & 7.0 & 9.8 & 15.6 & 21.0 & 22.9 \\
\hline 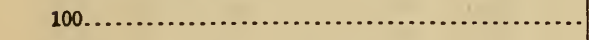 & 5.0 & 6.5 & 8.8 & 12.9 & 16.5 & 17.7 \\
\hline 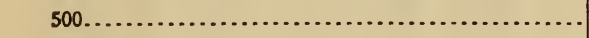 & 4.0 & 4.6 & 5.4 & 6.6 & 7.0 & 7.3 \\
\hline 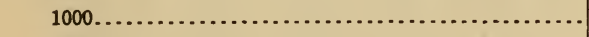 & 3.0 & 3.4 & 4.0 & 5.0 & 5.9 & 6.3 \\
\hline 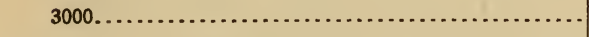 & 1.8 & 1.9 & 2.3 & 2.8 & 3.4 & ........ \\
\hline
\end{tabular}

${ }^{30}$ The values of inductance for D. C. correspond to the maximum values of the R. M. S. current given in the headings. 
2. COMPARISON OF OBSERVED AND COMPUTED VALUES FOR ZERO CURRENT

From the curves of Figs. 7,8 , and 9 we can obtain the initial values of the permeability for circular magnetization and by means of these values compute the effective resistances and inductances of the wires for zero current. In Table 8 these computed values are compared with the corresponding observed values obtained by extrapolating the results of experiment to zero current. The agreement between the two sets of values is fair; the differences may be due partly to the error in extrapolating and partly to a lack of homogeneity of the iron in the wires, which would require a somewhat different value of the minimum permeability to be used at different frequencies.

\section{TABLE 8}

Comparison of Observed and Computed Values of Effective Resistance and Inductance of Iron Wires for Zero Current

\begin{tabular}{|c|c|c|c|c|c|c|}
\hline \multirow{2}{*}{ Wire } & \multirow{2}{*}{$\begin{array}{c}\text { Permea- } \\
\text { bility }\end{array}$} & \multirow{2}{*}{ Frequency } & \multicolumn{2}{|c|}{ Resistance } & \multicolumn{2}{|c|}{ Internal inductance } \\
\hline & & & Observed & Computed & Observed & Computed \\
\hline \multirow{4}{*}{4 E. B. B.... } & \multirow{4}{*}{78} & 500 & 7.4 & 7.5 & 2.1 & 2.2 \\
\hline & & 1000 & 10.0 & 10.2 & 1.4 & 1.5 \\
\hline & & 3000 & 17.0 & 16.8 & 0.8 & 0.9 \\
\hline & & 500 & 9.9 & 10.3 & 2.4 & 2.8 \\
\hline \multirow[t]{3}{*}{4 Steel.... } & \multirow[t]{3}{*}{94} & 1000 & 13.2 & 14.0 & 1.7 & 2.0 \\
\hline & & 3000 & 21.9 & 23.1 & 1.0 & 1.1 \\
\hline & & 500 & 12.8 & 12.9 & 3.2 & 3.4 \\
\hline \multirow[t]{3}{*}{8 E. B. B... } & \multirow[t]{3}{*}{98} & 1000 & 17.2 & 17.5 & 2.4 & 2.4 \\
\hline & & 3000 & 27.0 & 28.7 & 1.7 & 1.4 \\
\hline & & 500 & 14.3 & 14.2 & 3.4 & 3.5 \\
\hline \multirow[t]{3}{*}{8 Steel... } & \multirow[t]{3}{*}{90} & 1000 & 19.0 & 19.2 & 2.4 & 2.6 \\
\hline & & 3000 & 30.0 & 31.2 & 1.5 & 1.5 \\
\hline & & 500 & 16.2 & 16.2 & 3.7 & 3.8 \\
\hline \multirow[t]{3}{*}{10 E. B. B.... } & \multirow[t]{3}{*}{93} & 1000 & 21.5 & 21.8 & 2.8 & 2.9 \\
\hline & & 3000 & 35.8 & 35.4 & 1.7 & 1.7 \\
\hline & & 500 & 18.4 & 18.3 & 3.7 & 3.9 \\
\hline \multirow[t]{2}{*}{10 Steel.... } & \multirow[t]{2}{*}{90} & 1000 & 24.1 & 24.2 & 2.7 & 3.1 \\
\hline & & 3000 & 38.0 & 39.2 & 1.7 & 1.8 \\
\hline
\end{tabular}




\section{EQUIVALENT PERMEABILITY-EFFECTS OF HYSTERESIS}

The values of equivalent permeability were computed in the manner outlined on page 230. The values shown in the curves of Figs. I9 and 20 were calculated from the measurements upon the

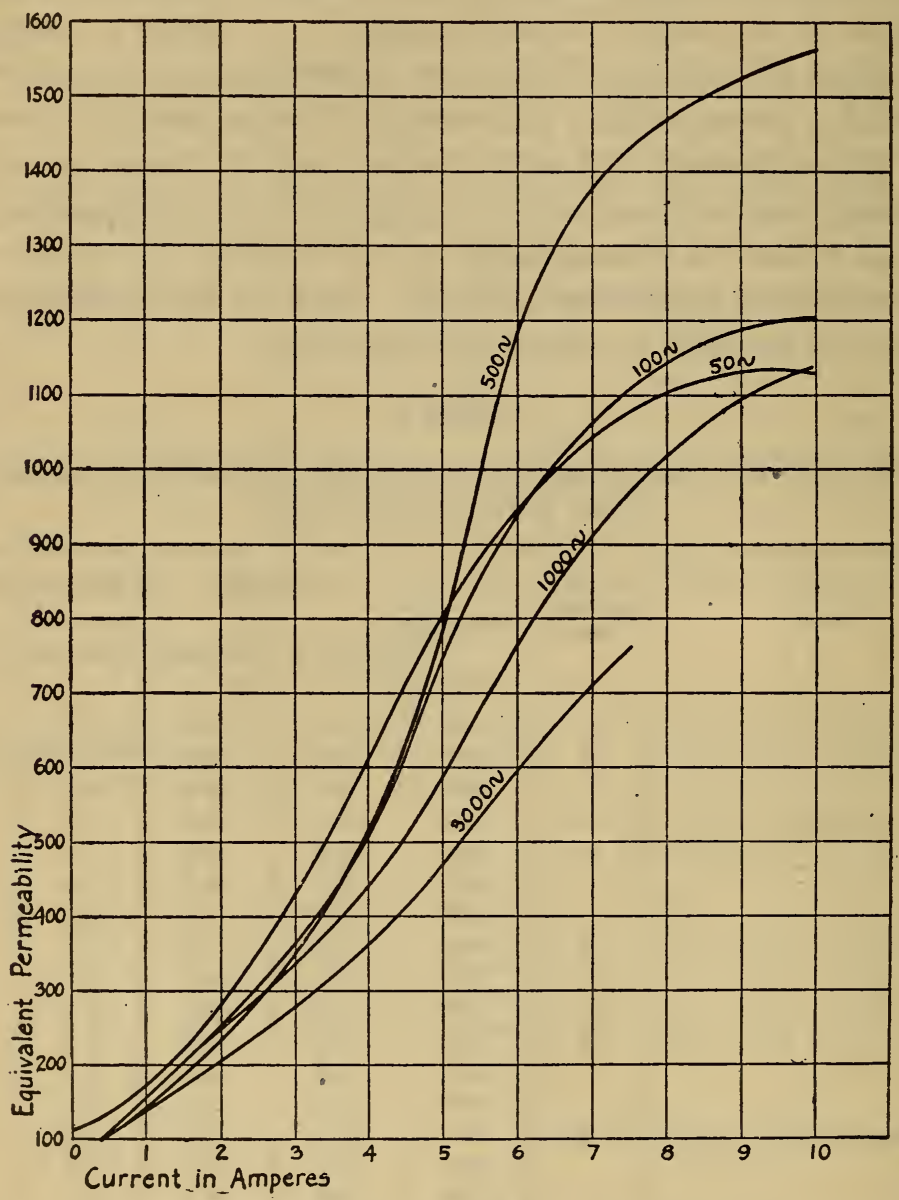

FIG. I9.-Equivalent permeability from resistance data

No. 4 E. B. B. wire. They are characteristic of the curves obtained for the other wires. It will be noted that the permeabilities calcuiated from resistance data reach extremely high values for 500 cycles, while at the same frequency the values obtained from the inductance data are low. From this we can obtain some 
interesting deductions with respect to the rôle played by hysteresis in determining the effective resistance and inductance of the wire.

The energy loss due to hysteresis increases the effective resistance of the conductor. Let us first assume that the distribution of current in the wire is unaltered as the frequency increases. Then the loss of energy per cycle would be a constant; the loss per second would increase proportional to the frequency. In such a case the resistance would increase proportional to the frequency.

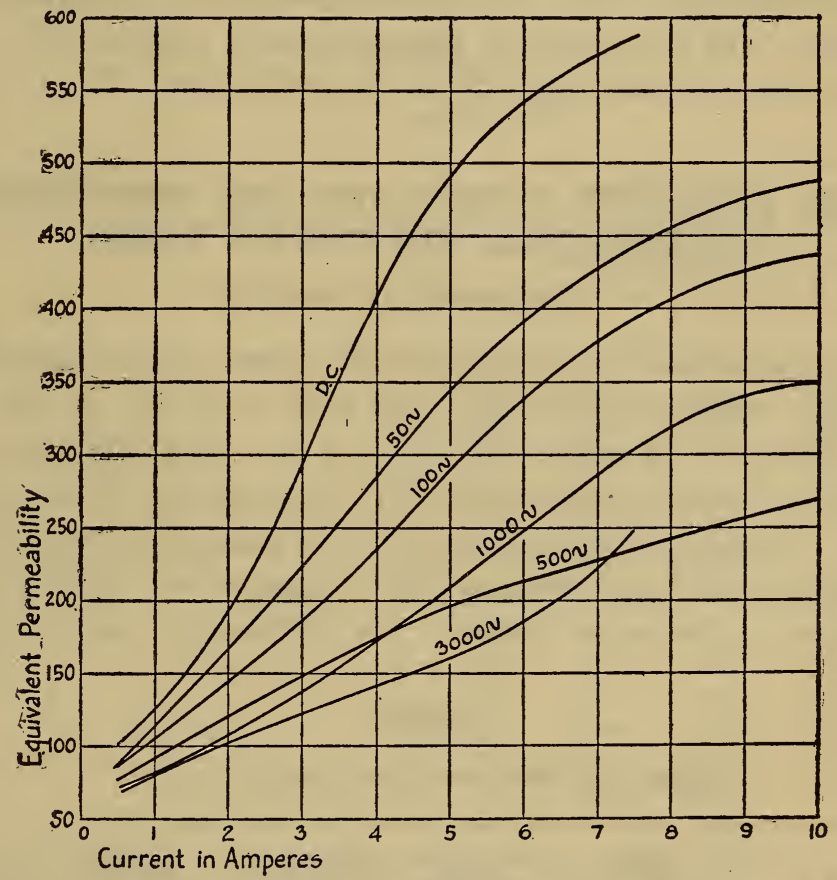

FIG. 20.-Equivalent permeability from inductance data

Actually, however, as the frequency increases, the current tends to concentrate more and more in the outer layers and the amplitude of the magnetizing force, and hence the hysteresis loss per cycle is diminished in the iron within the conductor. Thus, as the frequency increases these two effects oppose each other. At 500 cycles the hysteresis loss reaches a maximum, and on this account the equivalent permeability, as computed from the resistance data, attains high values. 
Now let us consider the effect of hysteresis upon the inductance of the wire. The inductance is determined solely by the distribution of the current. We can consider that the hysteresis loss is due to a counter emf. This counter emf would be a maximum at the outside of the conductor since there the amplitude of the magnetizing force, and hence the hysteresis loss is a maximum. On this account the outer layers would have a higher effective resistance than those within, and this would tend to equalize the current distribution over the cross section, i. e., to diminish the skin effect. On this account the equivalent permeability values for 500 cycles, as calculated from the inductance data, would be low.

\section{THE EFFECTIVE RESISTANCE AND INDUCTANCE OF COPPER-STEEL BIMETALLIC WIRES}

\section{EXPERIMENTAL RESULTS}

Three sizes of copper-steel bimetallic wires, the so-called copper clad wires, were investigated. The sizes were No. 4 , No. 8 , and No. Io A. W. G. Lengths of about $33 \mathrm{~m}$ of the wire were strung in a parallel wire arrangement with separations of about 30 or $40 \mathrm{~cm}$. No effect of separation upon the changes in resistance and inductance with the frequency was expected or looked for with separations as large as these. The following data may be of interest:

TABLE 9

Copper Clad Wires and Steel Core of No. 4

\begin{tabular}{|c|c|c|c|c|c|}
\hline Wire & $\begin{array}{l}\text { Mean } \\
\text { diameter } \\
\text { (mm) }\end{array}$ & $\begin{array}{c}\text { Calculated } \\
\text { shell } \\
\text { thickness (mm) }\end{array}$ & $\begin{array}{c}\text { Resistance per } \\
\text { kilometer- } \\
\text { ohms }\end{array}$ & $\begin{array}{l}\text { Resistivity } \\
\text { (microhm- } \\
\text { cm) }\end{array}$ & $\begin{array}{c}\text { Per cent } \\
\text { conductivity } \\
\text { (H.D. copper) }\end{array}$ \\
\hline $4 \ldots \ldots \ldots$ & 5.22 & 0.38 & 2.24 & 4.79 & 37.0 \\
\hline $8 \ldots \ldots \ldots$ & 3.27 & $0: 36$ & 4.42 & 3.71 & 47.7 \\
\hline $10 \ldots \ldots \ldots$ & 2.57 & 023 & 8.15 & 4.23 & 41.9 \\
\hline Core of $4 \ldots . . . .$. & 2.46 & .................. & 26.5 & 12.63 & 14.0 \\
\hline
\end{tabular}


The experimental results are given in Tables Io, II, and I 2 , the resistance in ohms per kilometer and the internal inductance in microhenrys per kilometer. The external inductance in centimeters for parallel wires of radius $\rho$ spacing $d$ and length $l$ all in centimeters is readily calculable from the formula

$$
L=4 l\left[\log _{e} \frac{d}{\rho}-\frac{d}{l}\right]
$$

where $l$ is the length of each wire.

TABLE 10

No. 4 Copper Clad

\begin{tabular}{|c|c|c|c|c|c|}
\hline \multirow[t]{2}{*}{ 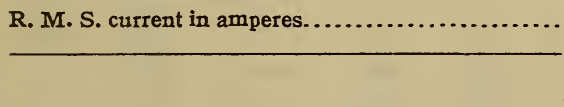 } & 0.5 & 1.5 & 3 & 5 & 10 \\
\hline & \multicolumn{5}{|c|}{ Resistance (ohms per kilometer) } \\
\hline \multicolumn{6}{|l|}{ Frequency: } \\
\hline D. C... & 2.24 & 2.24 & 2.24 & 2.24 & 2.24 \\
\hline 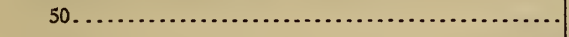 & 2.25 & 2.26 & 2.26 & 2.27 & 2.30 \\
\hline 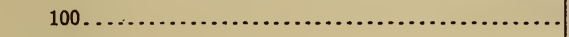 & 2.29 & 2.30 & 2.31 & 2.33 & 2.38 \\
\hline $500 \ldots$. & 2.60 & 2.61 & 2.63 & 2.64 & ........... \\
\hline 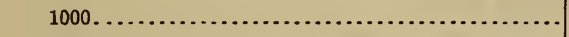 & 2.73 & 2. 75 & 2.75 & 2.76 & .......... \\
\hline \multirow{2}{*}{ 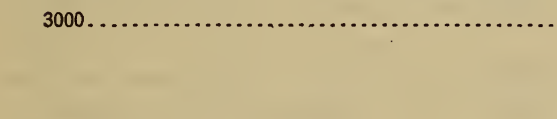 } & 2.94 & 2.92 & 2.93 & 2.94 & .......... \\
\hline & \multicolumn{5}{|c|}{ Internal inductance (microhenrys per kilometer) } \\
\hline D. C. ${ }^{21} \ldots .$. & 293 & 318 & 355 & 392 & \\
\hline $50 \ldots \ldots \ldots \ldots$ & 288 & 306 & 335 & 369 & 446 \\
\hline 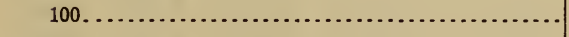 & 274 & 284 & 298 & 316 & 361 \\
\hline $500 \ldots \ldots \ldots \ldots \ldots \ldots \ldots$ & 123 & 122 & 118 & 112 & ........ \\
\hline 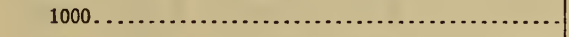 & 71 & 70 & 68 & 69 & n......... \\
\hline 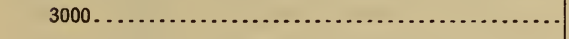 & 43 & 41 & 39 & 39 & ........... \\
\hline
\end{tabular}

${ }_{21}$ The values given for the D. C. inductance correspond to the maximum values of the R. M. S. currents given in the headings. 


\section{TABLE 11}

No. 8 Copper Clad

\begin{tabular}{|c|c|c|c|c|c|}
\hline 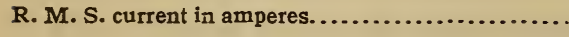 & 0.5 & 1.5 & 3 & 5 & 10 \\
\hline & \multicolumn{5}{|c|}{ Resistance (ohms per kilometer) } \\
\hline \multicolumn{6}{|l|}{ Frequency: } \\
\hline 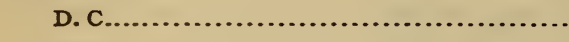 & 4.42 & 4.42 & 4.42 & 4.42 & 4.42 \\
\hline 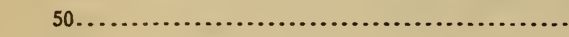 & N.... & ........ & ....... & ....... & \\
\hline 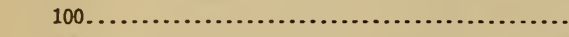 & 4.43 & 4.44 & 4.44 & 4.44 & $\cdots$ \\
\hline $500 \ldots \ldots \ldots \ldots \ldots \ldots \ldots \ldots \ldots \ldots \ldots \ldots \ldots \ldots \ldots \ldots \ldots \ldots \ldots \ldots$ & 4.58 & 4.59 & 4.60 & 4.62 & \\
\hline 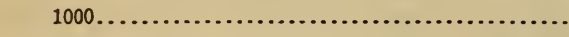 & 4.77 & 4.78 & 4.78 & 4.80 & \\
\hline \multirow[t]{2}{*}{ 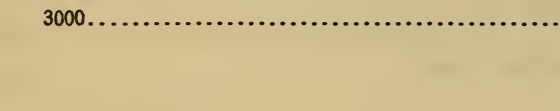 } & 5.04 & 5.04 & 5.04 & 5.02 & (........ \\
\hline & \multicolumn{5}{|c|}{ Internal inductance (microhenrys per kilometer) } \\
\hline $50 \ldots \ldots \ldots \ldots \ldots \ldots \ldots \ldots \ldots \ldots \ldots \ldots$ & 141 & 145 & 151 & 158 & 174 \\
\hline 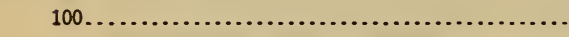 & 140 & 144 & 149 & 155 & \\
\hline 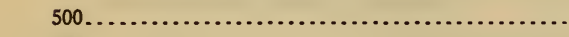 & 112 & 112 & 115 & 113 & ........... \\
\hline 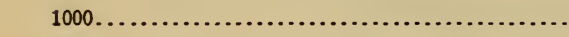 & 75 & 76 & 78 & 75 & ........ \\
\hline 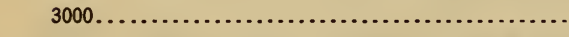 & 38 & 39 & 38 & 38 & (......... \\
\hline
\end{tabular}

TABLE 12

No. 10 Copper Clad

\begin{tabular}{|c|c|c|c|c|}
\hline 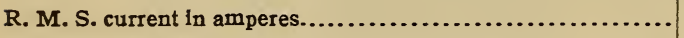 & 0.5 & 1.5 & 3 & 5 \\
\hline & Res & ace (oh & per kil & ter) \\
\hline \multicolumn{5}{|l|}{ Frequency: } \\
\hline 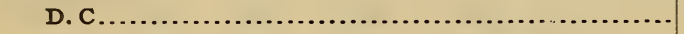 & 8.15 & 8.15 & 8.15 & 8.15 \\
\hline 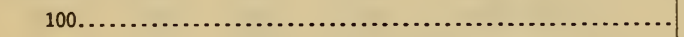 & 8.16 & 8.16 & 8.17 & 8.18 \\
\hline 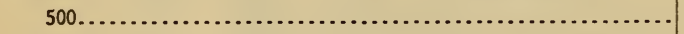 & 8.36 & 8.39 & 8.43 & 8.50 \\
\hline 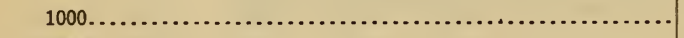 & 8.72 & 8. 75 & 8.79 & 8.84 \\
\hline \multirow[t]{2}{*}{ 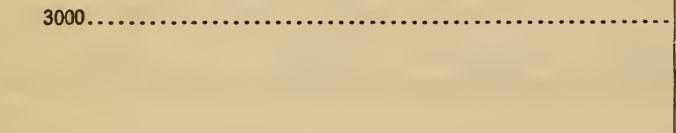 } & 9.38 & 9.38 & 9.39 & 9.39 \\
\hline & \multicolumn{4}{|c|}{$\begin{array}{c}\text { Internal inductance (microhenrys per } \\
\text { kilometer) }\end{array}$} \\
\hline 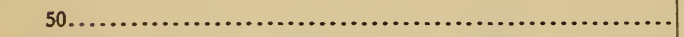 & 198 & 209 & 224 & 244 \\
\hline 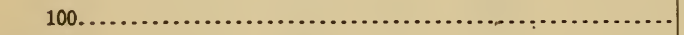 & 198 & 208 & 222 & 240 \\
\hline 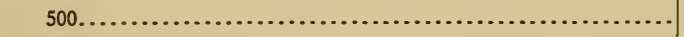 & 171 & 175 & 179 & 181 \\
\hline 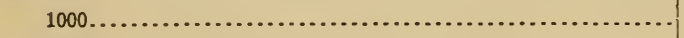 & 122 & 123 & 122 & 121 \\
\hline 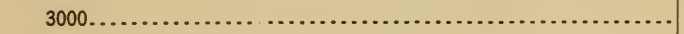 & 45 & 41 & 43 & 40 \\
\hline
\end{tabular}


The results are plotted in Figs. 21, 22, and 23. For low frequencies there is an increase in resistance and inductance with increasing current. This is due to an increase in the flux of induction in the steel core which increases the inductance as a direct effect and increases the resistance indirectly on account of the skin effect. The latter tends to reduce the inductance, but is outweighed by the direct effect. As the frequency increases the
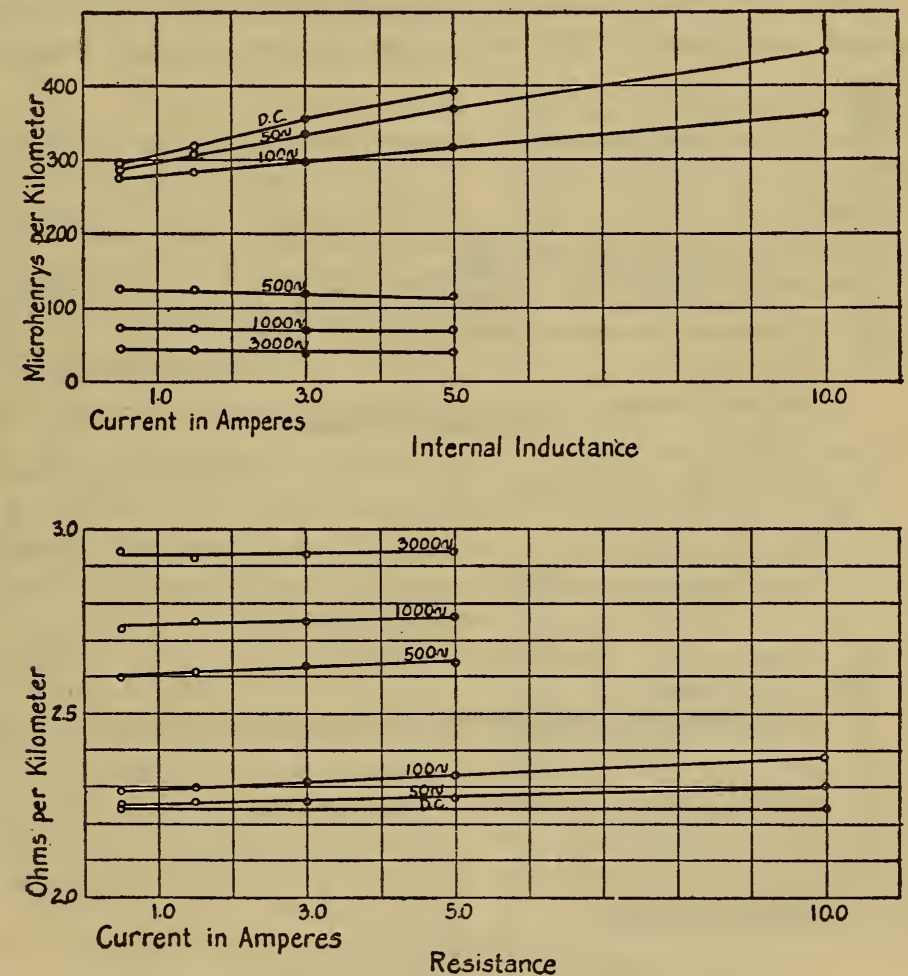

FIG. 21.-No. 4 copper clad wire

resistance and inductance become independent of the current strength. This is due to the fact that the impedance of the core has become so high relative to the impedance of the shell that very large changes in the former would be required to produce appreciable changes in the combined impedance. At very high frequencies, of course, the copper clad wire would behave exactly the same as a solid copper conductor. Similarly, the higher the 
conductivity of the copper-steel wire the less the dependance of the resistance and inductance upon the current strength, in this case also approaching as a limit the solid copper conductor.

\section{A COMPARISON OF OBSERVED AND COMPUTED VALUES}

The experimental determinations of the effective resistance and inductance with a current of 0.5 ampere may very well be taken to represent the case where the permeability of the core is a minimum and constant. The maximum values of the magnetizing
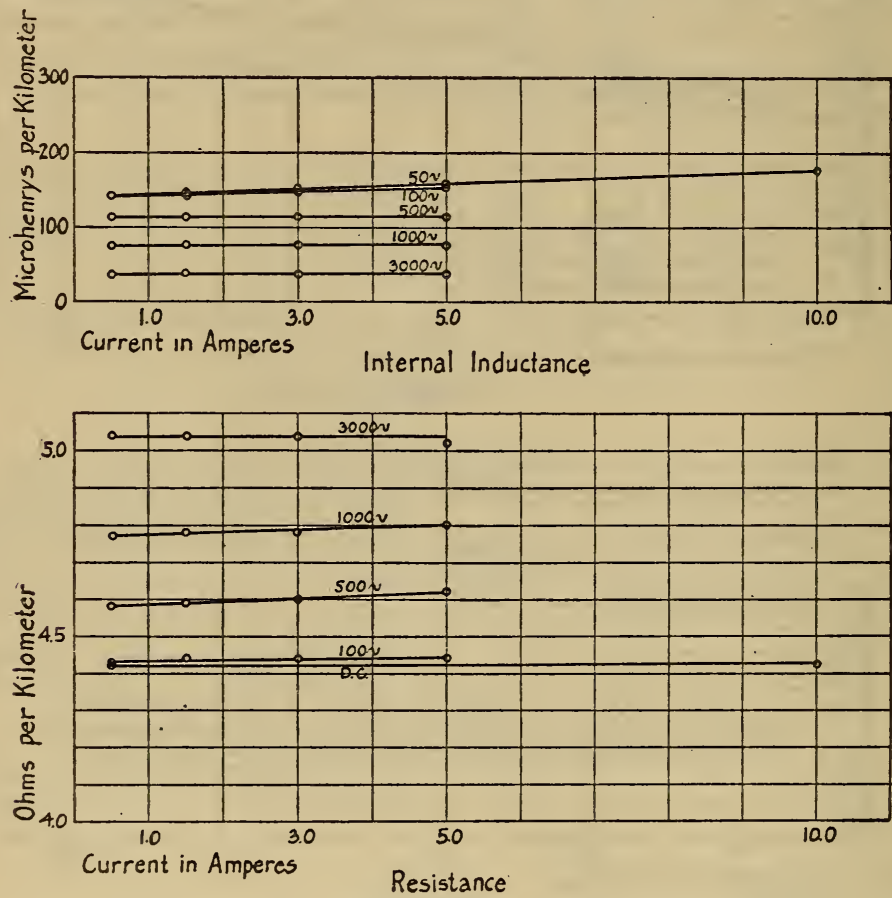

FIG. 22.-No. 8 copper clad wire

force in the core for direct current of $0.5 \times \sqrt{2}$ ampere are, roughly, $0.18,0.20$, and 0.32 C. G. S. units for the No. 4, No. 8, and No. ro wires, respectively. From Fig. I i it may be seen that the permeabilities for these magnetizing forces are practically the minimum.

In order to compute the values of the effective resistance and inductance for a given frequency, it is necessary to know the 
radius, resistivity, and permeability of the core. Measurements upon the steel wire which was obtained by turning down the No. 4 Copper Clad wire gave the resistivity of the steel as 12.63 microhm-centimeter. The resistivity of hard-drawn copper was taken as 2.7 per cent higher than the international annealed copper standard;22 i. e., as $1.77 \mathrm{I}$ microhm-centimeter. The resistivities of both the steel and the copper will vary irregularly from one wire to another, due to composition, heat treatment, and drawing. The above values were, however, assumed for all three wires in the calculations. From these values-the measured resistances on direct current and the radii of the wires-we obtain the data in Table 13.

The first calculations were made before the permeability curves of Fig. I I were obtained for the No. 8 and No. ro sizes, and the value $\mu=90$ determined from the core of the No. 4 wire was used for all three wires.

Using the above data the effective resistance and internal inductance of the core was calculated for the frequencies 100,500 , rooo, and 3000 by the formulas (3) and (4) and the inductances $L_{1}, L_{2}$, and $M$ by the formulas (5), (6), and (7). In formula (5)
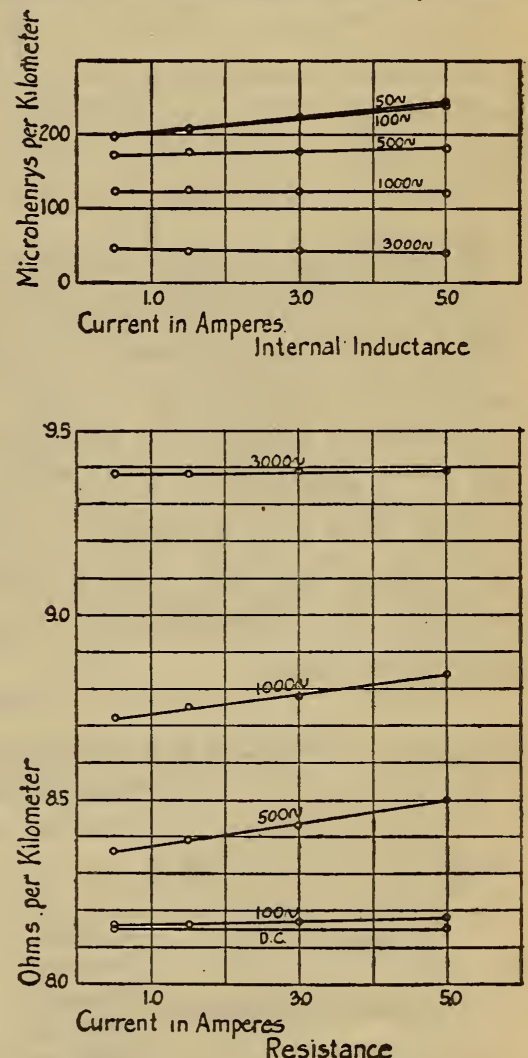

FIG. 23.-No.Io copper clad wire in place of $\frac{\mu}{2}$ the computed value of the internal inductance of the core was substituted. Finally the effective resistances and internal inductances of the copper-clad wires were computed by formulas (8) and (9). The experimental values for 0.5 ampere 
and the computed values are compared in Table $\mathrm{I} 4$, the resistances being given in ohms per kilometer and the internal inductances in microhenrys per kilometer.

TABLE 13

\begin{tabular}{|c|c|c|c|c|c|}
\hline \multirow{2}{*}{ Wire } & \multirow{2}{*}{$\begin{array}{c}\text { Radius } \\
\text { (centime- } \\
\text { ter) }\end{array}$} & \multirow{2}{*}{$\begin{array}{l}\text { Radius of } \\
\text { core (cen- } \\
\text { timeter) }\end{array}$} & \multirow{2}{*}{$\begin{array}{c}\text { Thickness } \\
\text { of shell } \\
\text { (centime- } \\
\text { ter) }\end{array}$} & \multicolumn{2}{|c|}{$\begin{array}{c}\text { Direct-current } \\
\text { resistance } \\
\text { (ohms per kilometer) }\end{array}$} \\
\hline & & & & Core & Shell \\
\hline No. $4, \ldots \ldots \ldots \ldots \ldots$ & 0.261 & 0.223 & 0.038 & 8.06 & 3.10 \\
\hline No. $8 . . . . . . . . .$. & 0.164 & 0.128 & 0.036 & 24.65 & 5.39 \\
\hline 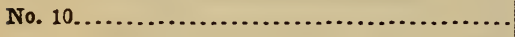 & 0.129 & 0.106 & 0.023 & 35.95 & 10.53 \\
\hline
\end{tabular}

It will be noted that two sets of computed values are given for the No. Io wire. The first set (I) was computed from the assumed value $\mu=90$, as explained above. The determination of the permeability curves given in Fig. I I was then made and resulted in values of 85 and 70 for the initial values of the permeabilities of the No. 8 and No. Io wires, respectively. The calculation for the No. Io wire was repeated, using the value 70 , which resulted in the second set (2), which show considerably closer agreement between the observed and computed values, in particular for the self-inductance.

\section{TABLE 14}

Comparison of Observed and Computed Values of Effective Resistance and Internal Inductance of Copper-Clad Wires

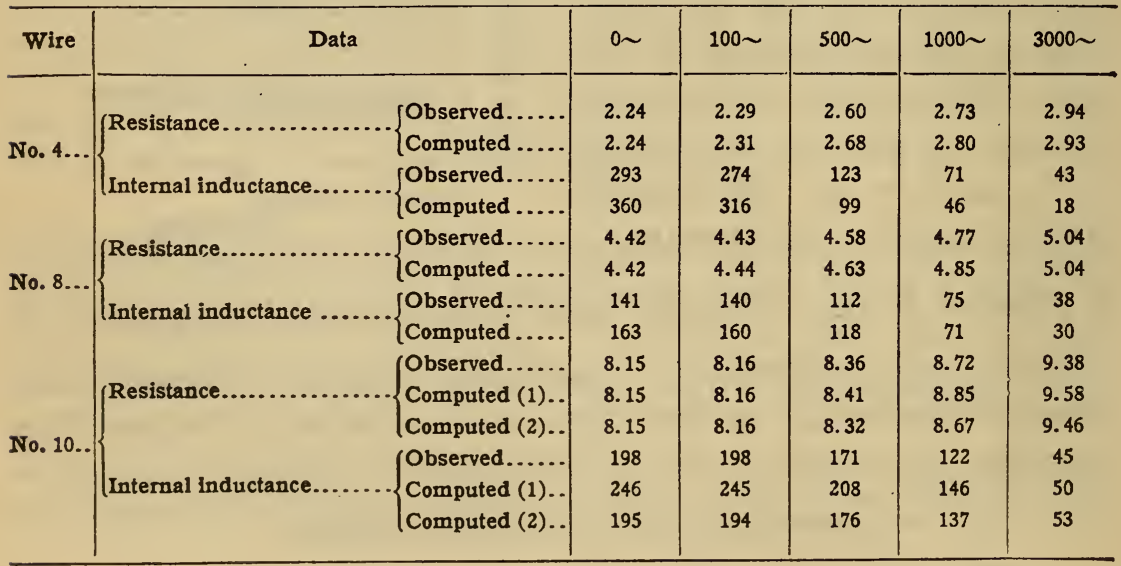




\section{EFFECT OF NONCIRCULARITY OF THE CORE}

It is of interest to inquire into the possible effects of departures of the core of actual wires from the circular cross section assumed in the calculation. At low frequencies the core plays its most important part in determining the resistance and inductance of the wire, and this is especially true when the shell is thin. The inductance is the more strongly influenced, as may be seen from the above two values of the inductance for the No. Io wire at zero frequency for $\mu=90$ and $\mu=70$. Here the change in $\mu$ is 22 per cent and the change in the inductance about $2 \mathrm{I}$ per cent. As the frequency increases, the resistance and inductance of the wire approach the values for the shell. It would seem that departure of the core from circularity would have the effect of decreasing the effective radius of the core and increasing the effective thickness of the shell; for when the core is circular the lines of force would run either entirely through steel or entirely through copper, the steel would have its maximum effect, making the total induction internal to the wire a maximum. When, however, the core is noncircular, some of the lines of force would run partly through steel and partly through copper, the reluctance of the path would be determined practically entirely by the copper, and the effect of this steel would hardly be any more than if it were a nonmagnetic material. It could then be considered a part of the shell. The effects due to noncircularity would be the following:

I. A decided decrease in the self-inductance for direct current and low frequencies, due to the decrease of the core inductance.

2. A reduction of the magnitude of the skin effect for intermediate frequencies, due to a decrease in the effective radius of the core.

3. An increase in the limiting value of the inductance for higher frequencies, due to the increase in the effective thickness of the shell.

The limiting value of the resistance for high frequency would, however, not be changed very much, due to the increase in the effective thickness of the shell, for this increase is brought about by the addition of a material of high resistivity; but the limiting value ought to be attained somewhat slower. 
The differences between the computed and experimental values for the No. 4 wire, in which the core departs badly from circularity, are exactly such as to be explained from this cause. The agreement in the resistance at 3000 cycles is probably bettered somewhat by skin effect in the shell which brings the observed value up to the computed, in which this skin effect is neglected.

The noncircularity of the core is an advantage at low frequencies from the standpoint of practice, since it reduces both the inductance and resistance of the wire. It is probable that the increase in resistance and inductance due to increasing current strength is likewise diminished by the noncircularity of the core. This suggests the possible desirability of giving the core a cross section which would have the effect of a considerable departure from circularity, as might be accomplished by having a slotted cross section like that in Fig. 24. This would approximate somewhat

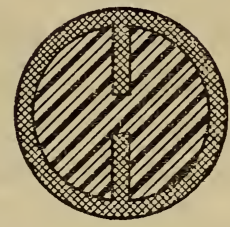

Fig. 24.-Slotted cross section

a conductor having a core of high resistivity, nonmagnetic metal. In such a conductor the internal inductance would be lower than in a solid conductor, and both the resistance and inductance would be independent of the current strength. Further, as the frequency increased the per cent conductivity relative to a solid copper conductor would increase throughout the whole range, whereas the opposite is the case in the lower range of frequencies for the wire as now made.

In Fig. 25 are shown the cross sections of the Nos. 4, 8, and Io wires used in the measurements. These drawings were obtained from photomicrographs. ${ }^{23}$ One sample was taken from each end of the 30-m length of wire. The photographs show a considerable deviation of the core from circularity (especially for the No. 4),

${ }^{23}$ The samples were prepared by the metallurgical division of the Bureau of Standards. The photographs were taken by this division and the Bureau photographer. 
together with a fair constancy of the cross section of the steel in a particular wire both in shape and area.

In making the calculations for effective resistance and inductance of the copper-clad wires it seemed reasonable to assume that the resistivity of the copper would be very nearly constant from
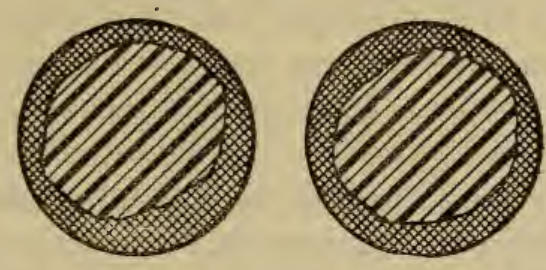

No. Io
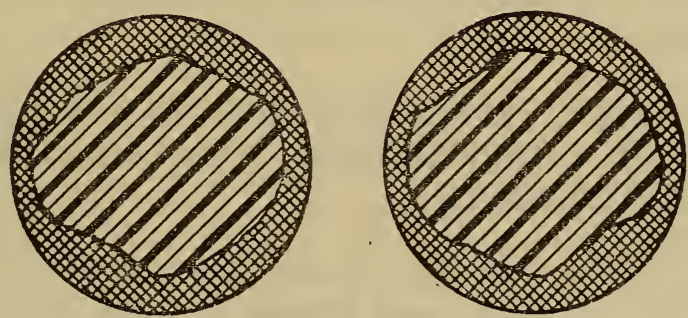

No. 8
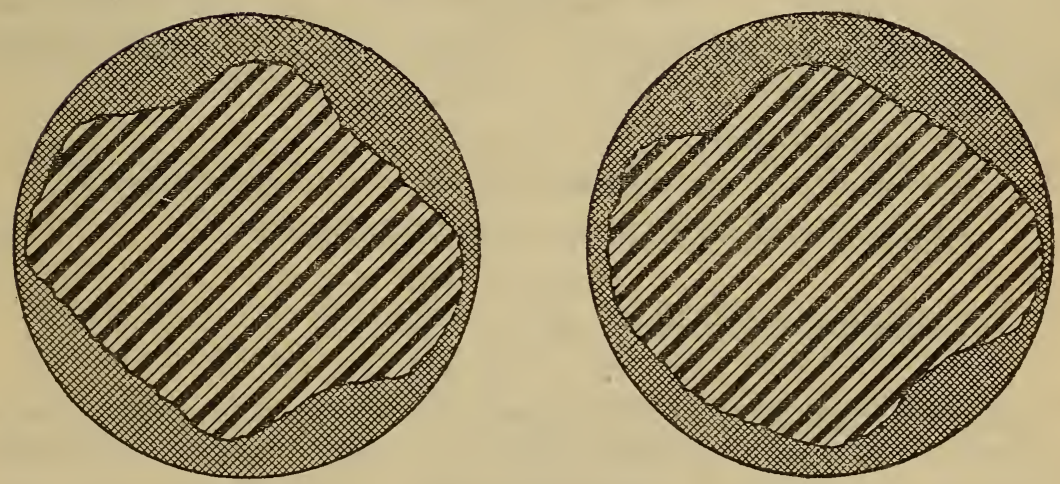

No. 4

FIG. 25.-Cross section of copper clad wires from photomicrographs

wire to wire; the resistivity of the steel, however, was considered to be susceptible of considerable variations. In order to obtain some information in this respect, the photomicrographs were measured with a planimeter and the ratio of $r_{2}$ to $r_{1}$ determined for all three wires. This measured ratio agreed very closely with 
that previously computed for the No. 8 wire, but for the Nos. 4 and ro was several per cent higher. Since a direct measurement of conductivity had been made upon the steel of the No. 4 wire, this meant that the copper was considerably lower in conductivity than the assumed value-i. e., 97.5 per cent of standard annealed copper. A short strip of copper was then sawed from the No. 4 wire, and the conductivity was found to be only about 84.8 per cent of annealed copper. It is therefore probable that the copper in the No. Io wire was also low in conductivity, but that the No. 8 was normal. The effect upon the computed effective resistances is small; the computed inductances, however, would be affected more strongly, and in such a way as to reduce the differences for the No. 4 wire.

\section{WIRE TABLES. EFFECTIVE RESISTANCE AND INDUCT- ANCE OF COPPER-STEEL BIMETALLIC WIRES FOR SMALL CURRENTS}

By means of the formulas (8) and (9) the effective resistance and inductance of copper-steel bimetallic wires Nos. o, 2, 4, 6, 8, Io, and I 2 A. W. G. were calculated for 30,40 , and 50 per cent conductivities (of hard-drawn copper) and frequencies ranging from zero to 3000 .

It was assumed that

Resistivity of hard-drawn copper $=1.77 \mathrm{I}$ microhm-cm.

Resistivity of steel core $=\mathrm{I} 2.63$ microhm-cm.

Permeability of core $\left\{\begin{array}{l}=90 \text { for Nos. o, } 2,4 \\ =85 \text { for Nos. } 6,8 \\ =7 \text { o for Nos. IO, I } 2 .\end{array}\right.$

Mainly on account of the departure of the core from noncircularity the values of inductance for actual wires may differ considerably from the computed values. Deviations of the permeability of the core and conductivity of the core and shell from the assumed values may also cause differences. The resistance values are not as strongly affected by these variations as the inductance values and the computed values of resistance should fit actual wires to a few per cent. 
Table ${ }_{5}$ gives the resistance values in ohms per kilometer, Table 16 the per cent increase in resistance from the direct-current values, and Table 17 the internal inductance values to two significant figures in microhenrys per kilometer. In Fig. 26 the per cent increase in resistance is plotted with respect to frequency, and in Fig. 27 the internal inductance values are also plotted as a

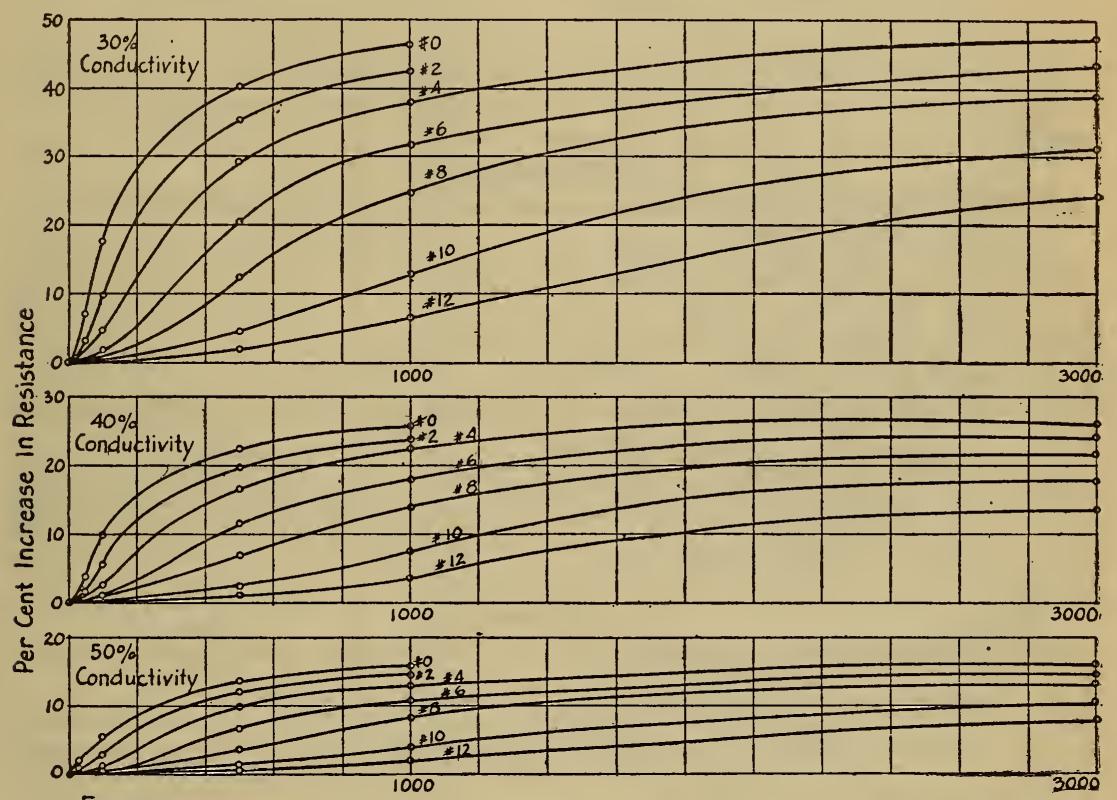

Frequency

FIG. 26.-Effective resistance of copper-steel wires. Computed

function of the frequency. Fig. 28 shows the variation of the per cent increase in resistance with the conductivity, and from this figure, by interpolation, values may be obtained for intermediate conductivities. It will be noted that ordinary deviations of the wire size from the nominal size for the gage number will not appreciably affect the per cent increase in resistance. 

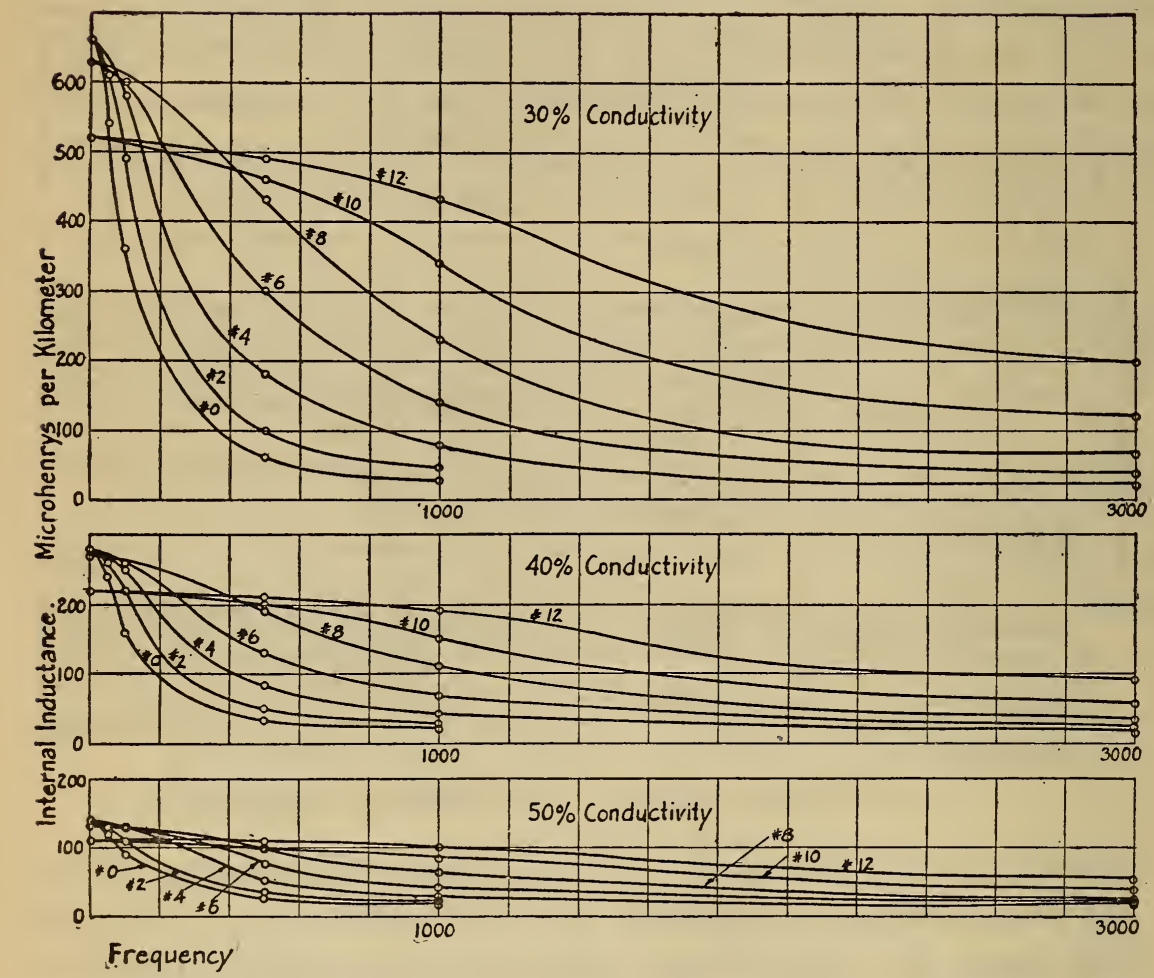

Fig. 27.-Computed internal inductance. Copper-steel wires 

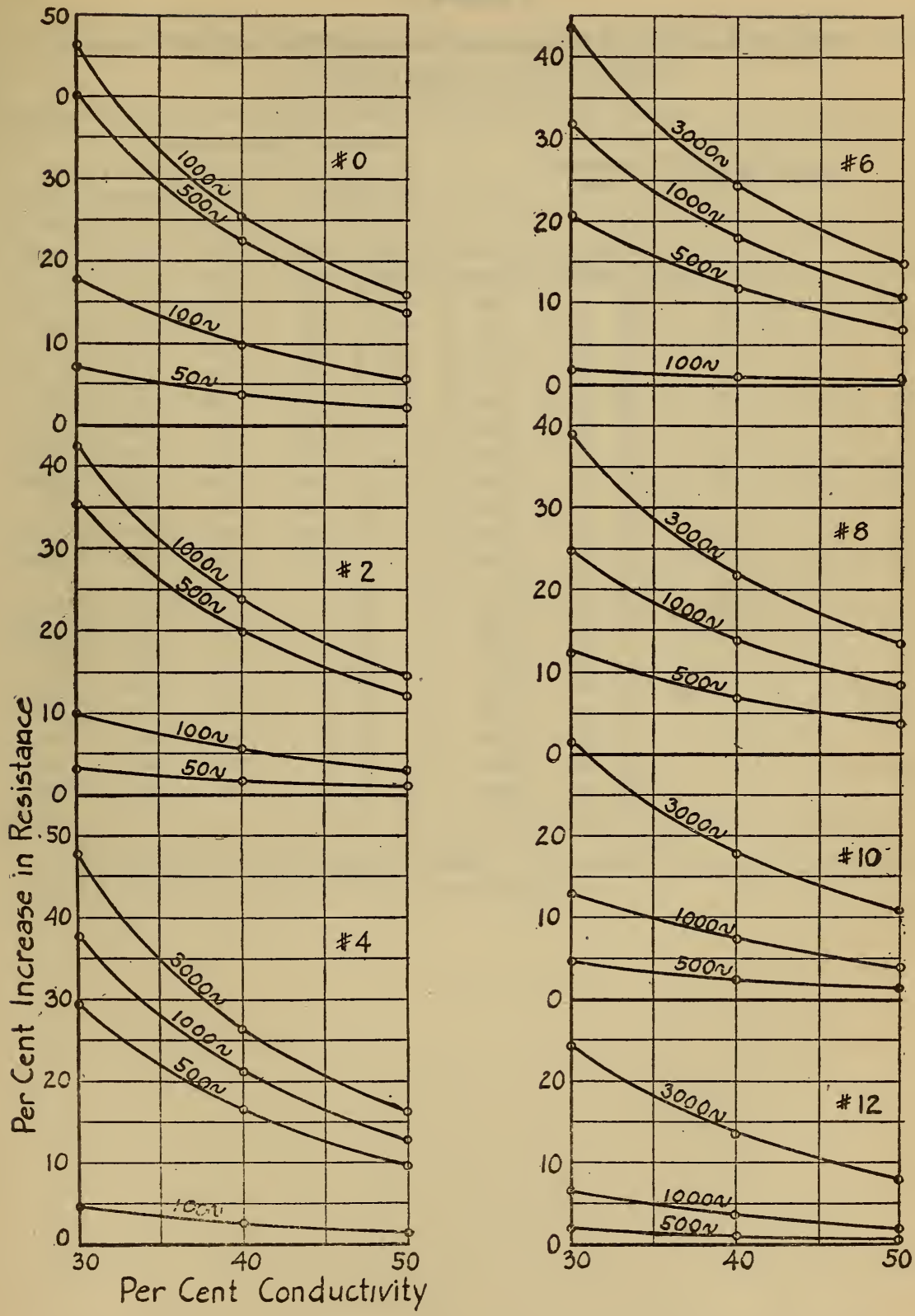

FIG. 28.-Effective resistance of copper-steel wires as a function of the conductivity 
TABLE 15

\section{Effective Resistance of Copper-Steel Bimetallic Wires for Small Currents}

[Computed by the formulas 8 and 9, p. 235]

\begin{tabular}{|c|c|c|c|c|c|c|c|}
\hline \multirow{2}{*}{ Wire (A. W. G.) } & \multirow{2}{*}{$\begin{array}{l}\text { Conduc- } \\
\text { tivity }\end{array}$} & \multicolumn{6}{|c|}{ Frequency (cycles per second) } \\
\hline & & $0 \sim$ & $50 \sim$ & $100 \sim$ & $500 \sim$ & $1000 \sim$ & $3000 \sim$ \\
\hline & $\begin{array}{l}\text { Per cent } \\
\int \begin{array}{l}30\end{array}\end{array}$ & $\begin{array}{l}Q / \mathrm{km} \\
1.10\end{array}$ & $\begin{array}{l}2 / \mathrm{km} \\
1.18\end{array}$ & $\begin{array}{l}Q / \mathrm{km} \\
1.30\end{array}$ & $\begin{array}{l}Q / \mathrm{km} \\
1.55\end{array}$ & $\begin{array}{l}Q / \mathrm{km} \\
1.61\end{array}$ & $\begin{array}{c}\Omega / \mathrm{km} \\
\ldots . . .\end{array}$ \\
\hline \multirow[t]{3}{*}{ No. 0 . } & 40 & 0.83 & 0.86 & 0.91 & 1.01 & 1.04 & ............ \\
\hline & 50 & 0.66 & 0.68 & 0.70 & 0.75 & 0.77 & ............. \\
\hline & 30 & 1.75 & 1.81 & 1.93 & 2. 37 & 2.50 & ............ \\
\hline \multirow[t]{3}{*}{ No. 2 . } & 40 & 1.32 & 1.34 & 1.39 & i. 58 & 1.63 & ............ \\
\hline & 50 & 1.05 & 1.06 & 1.08 & 1.18 & 1.21 & ............ \\
\hline & 30 & 2.79 & & 2.92 & 3.61 & 3.85 & 4.12 \\
\hline \multirow[t]{3}{*}{ No. 4.} & 40 & 2.09 & & 2.15 & 2.44 & 2.54 & 2.64 \\
\hline & 50 & 1.67 & & 1.70 & 1.84 & 1.89 & 1.94 \\
\hline & 30 & 4. 44 & & 4.52 & 5.3 & 5.8 & 6.4 \\
\hline \multirow[t]{3}{*}{ No. 6} & 40 & 3.33 & & 3.36 & 3.71 & 3.92 & 4.13 \\
\hline & 50 & 2.66 & & 2.68 & 2.84 & 2.95 & 3.06 \\
\hline & 30 & 7.1 & & $\cdots$ & 7.9 & 8.8 & 9.8 \\
\hline \multirow[t]{3}{*}{ No. 8} & 40 & 5.3 & & & 5.7 & 6.0 & 6.4 \\
\hline & 50 & 4.23 & & & 4. 39 & 4.57 & 4.80 \\
\hline & 30 & 11.2 & & & 11.7 & 12.7 & 14.7 \\
\hline \multirow[t]{3}{*}{ No. $10 \ldots$} & 40 & 8.4 & & & 8.6 & 9.0 & 9.9 \\
\hline & 50 & 6.7 & & & 6.8 & 7.0 & 7.5 \\
\hline & 30 & 17.8 & & 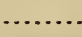 & 18.2 & 19.0 & 22.1 \\
\hline \multirow[t]{2}{*}{ No. $12 \ldots$} & 40 & 13.4 & & & 13.5 & 13.9 & 15.2 \\
\hline & 50 & 10.7 & . & . & 10.8 & 10.9 & 11.6 \\
\hline
\end{tabular}


TABLE 16

Increase in Effective Resistances of Copper-Steel Bimetallic Wires From Direct Current Values, for Small Currents

[Computed by the formulas 8 and 9, p. 235]

\begin{tabular}{|c|c|c|c|c|c|c|c|}
\hline \multirow{2}{*}{ Wire (A. W. G.) } & \multirow{2}{*}{$\begin{array}{c}\text { Conduc- } \\
\text { tivity }\end{array}$} & \multicolumn{6}{|c|}{ Frequency (cycles per second) } \\
\hline & & $50 \sim$ & $100 \sim$ & $500 \sim$ & $1000 \sim$ & $3000 \sim$ & $\infty 24$ \\
\hline & $\begin{array}{l}\text { Per cent } \\
30\end{array}$ & $\begin{array}{c}\text { Per cent } \\
7\end{array}$ & $\begin{array}{c}\text { Per cent } \\
18\end{array}$ & $\begin{array}{c}\text { Per cent } \\
40\end{array}$ & $\begin{array}{c}\text { Per cent } \\
46\end{array}$ & $\begin{array}{l}\text { Per cent } \\
\ldots .\end{array}$ & $\begin{array}{c}\text { Per cent } \\
61\end{array}$ \\
\hline \multirow[t]{3}{*}{ No. $0 . .}$. & 40 & 4 & 10 & 22 & 26 & .......... & 32 \\
\hline & 50 & 2 & 6 & 14 & 16 & ........... & 19 \\
\hline & 30 & 3 & 10 & 35 & 42 & ........... & 61 \\
\hline \multirow[t]{3}{*}{ No. 2... } & 40 & 2 & 5 & 20 & 24 & .......... & 32 \\
\hline & 50 & 1 & 3 & 12 & 14 & ......... & 19 \\
\hline & 30 & & 5 & 29 & 38 & 48 & 61 \\
\hline \multirow[t]{3}{*}{ No. $4 \ldots$} & 40 & ...... & 3 & 17 & 21 & 26 & 32 \\
\hline & 50 & ...... & 1 & 10 & 13 & 16 & 19 \\
\hline & 30 & ....... & 2 & 21 & 32 & 43 & 61 \\
\hline \multirow[t]{3}{*}{ No. $6 . .}$. & 40 & ........ & 1 & 12 & 18 & 24 & 32 \\
\hline & 50 & ........ & 0.5 & 7 & 11 & 15 & 19 \\
\hline & 30 & & & 12 & 25 & 39 & 61 \\
\hline \multirow[t]{3}{*}{ No. $8 . .}$. & 40 & ....... & 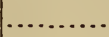 & 7 & 14 & 22 & 32 \\
\hline & 50 & ....... & $\ldots \ldots$ & 4 & 8 & 13 & 19 \\
\hline & 30 & ........ & 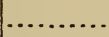 & 4 & 13 & 31 & 61 \\
\hline \multirow[t]{3}{*}{ No. $10 .}$. & 40 & ......... & .......... & 2 & 7 & 18 & 32 \\
\hline & 50 & ........ & ............. & 1 & 4 & 11 & 19 \\
\hline & 30 & ............ & ............ & 2 & 7 & 24 & 61 \\
\hline \multirow[t]{2}{*}{ No. $12 .}$. & 40 & ............. & & 1 & 4 & 14 & 32 \\
\hline & 50 & ........... & & 0.5 & 2 & 8 & 19 \\
\hline
\end{tabular}

24 The limiting value by this method of calculation. It is determined by the ratio of the resistance of the shell to the total resistance of the wire for direct current. 
TABLE 17

Effective Internal Inductance of Copper-Steel Bimetallic Wires for Small Currents ${ }^{25}$

[Computed by the formulas 8 and 9, p. 235]

\begin{tabular}{|c|c|c|c|c|c|c|c|c|}
\hline \multirow{2}{*}{ Wire A. W. G. } & \multirow{2}{*}{$\begin{array}{l}\text { Conduc- } \\
\text { tivity }\end{array}$} & \multicolumn{7}{|c|}{ Frequency (cycles per second) } \\
\hline & & $0 \sim$ & $50 \sim$ & $100 \sim$ & $500 \sim$ & $1000 \sim$ & $3000 \sim$ & $\infty 26$ \\
\hline \multirow{5}{*}{ No. $0 \ldots$} & Per cent & $\mu^{\mathrm{h} / \mathrm{km}}$ & $\mu \mathrm{h} / \mathrm{km}$ & $\mu \mathrm{h} / \mathrm{km}$ & $\mu \mathrm{h} / \mathrm{km}$ & $\mu \mathrm{h} / \mathrm{km}$ & $\mu \mathrm{h} / \mathrm{km}$ & $\mu \mathrm{h} / \mathrm{km}$ \\
\hline & 30 & 660 & 540 & 360 & 61 & 28 & & 7 \\
\hline & 40 & 280 & 240 & 160 & 32 & 20 & & 11 \\
\hline & 50 & 140 & 120 & 90 & 27 & 20 & & 16 \\
\hline & 30 & 660 & 610 & 490 & 100 & 47 & .. & 7 \\
\hline \multirow[t]{3}{*}{ No. $2 \ldots$} & 40 & 280 & 260 & 220 & 50 & 27. & & 11 \\
\hline & 50 & 140 & 130 & 110 & 36 & 24 & $\ldots$ & 16 \\
\hline & 30 & 660 & & 580 & 180 & 79 & 24 & 7 \\
\hline \multirow[t]{3}{*}{ No. 4.... } & 40 & 280 & ......... & 250 & 83 & 40 & 18 & 11 \\
\hline & $50^{\circ}$ & 140 & & 130 & 53 & 31 & 19 & 16 \\
\hline & 30 & 630 & ....... & 600 & 300 & 140 & 39 & 7 \\
\hline \multirow[t]{3}{*}{ No. $6 \ldots$} & 40 & 270 & & 260 & 130 & 66 & 24 & 11 \\
\hline & 50 & 130 & $\ldots$. & 130 & 77 & 44 & 23 & 16 \\
\hline & 30 & 630 & & & 430 & 230 & 66 & 7 \\
\hline \multirow[t]{3}{*}{ No. $8 \ldots$} & 40 & 270 & ...... & & 190 & 110 & 35 & 11 \\
\hline & 50 & 130 & & 5 & 100 & 65 & 28 & 16 \\
\hline & 30 & 520 & & & 460 & 340 & 120 & 7 \\
\hline \multirow[t]{3}{*}{ No. $10 \ldots$} & 40 & 220 & & & 200 & 150 & 58 & 11 \\
\hline & 50 & 110 & & & 100 & 85 & 40 & 16 \\
\hline & 30 & 520 & & & 490 & 430 & 200 & 7 \\
\hline \multirow[t]{2}{*}{ No. $12 .}$. & 40 & 220 & $\ldots$. & . & 210 & 190 & 93 & 11 \\
\hline & 50 & 110 & & & 110 & 100 & 57 & 16 \\
\hline
\end{tabular}

25 The values were calculated on the assumption of circular cross section of core and definite values of permeability of core material and of resistivity of core and shell. The deviations of the values for actual wires from those in the table may be considerable.

${ }^{26}$ The limiting value by this method of calculation. It is the internal inductance of the shell.

\section{SUMMARY}

I. A. formula is derived which permits the exact permeability curve of a homogeneous iron wire for circular magnetization to be obtained from measurements of the self-inductance of the wire with direct current. Determinations and comparisons of axial and circular permeability curves are made for a number of wires. In some cases the two curves show fair agreement and in others considerable differences. The latter are probably due to the nonhomogeneity or nonistropy of the material. 
2. The effective resistances and inductances of a number of samples of iron telegraph and telephone wires are determined by a bridge method in the range of frequencies from 50 to 3000 cycles per second and with current strengths varying from 0.5 to Io amperes. The experimental results are interpolated to zero current and compared with values calculated from the minimum permeabilities of the materials.

3. Formulas are derived for the effective resistance and inductance of bimetallic wires for the case of constant permeability of the materials. A number of copper-steel bimetallic wires are investigated experimentally, and the results for low currents are compared with the values obtained by computation. A table of computed values of effective resistance and inductance for various frequencies is given for copper-steel wires of 30,40 , and 50 per cent conductivity and for sizes Nos. o, 2, 4, 6, 8, I0, and I 2 A. W. G.

In conclusion I desire to express my thanks to Dr. E. B. Rosa and Dr. H. L. Curtis for their many valuable suggestions.

Washington, April I4, I9I 5. 